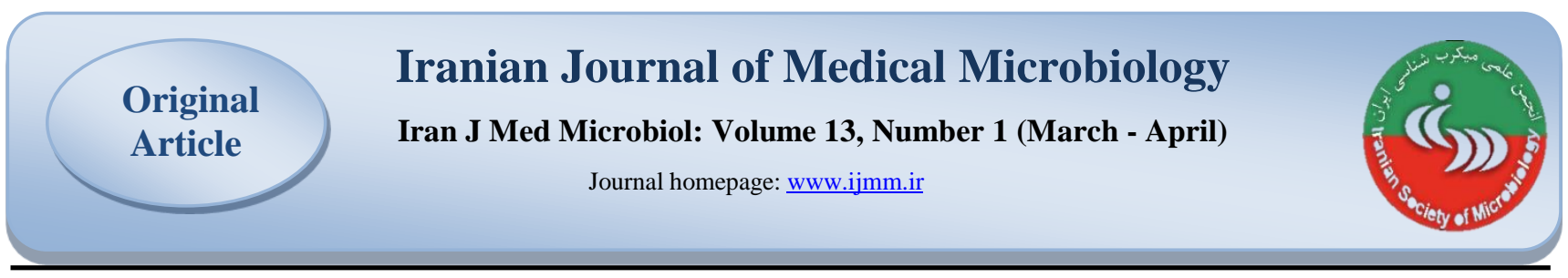

\title{
Assessment of Lactobacillus Delbruekii and Bifidobacterium Animalis Abilities to Absorb Aflatoxin $M_{1}$ from Milk
}

\author{
Maryam Namvar Rad ${ }^{1}$, Vadood Razavilar ${ }^{1 *}$, Seyed Amir Ali Anvar ${ }^{1}$, Behrouz Akbari-Adergani²
}

1. Department of Food Hygiene, Faculty of Veterinary Medicine, Science and Research Branch, Islamic Azad University, Tehran, Iran

2. Food and Drug Laboratory Research Center, Food and Drug Administration, Ministry of Health and Medical Education, Tehran, Iran

\section{Article Information}

\section{Article Subject: \\ Food Microbiology}

DOI: $10.30699 /$ ijmm.13.1.44

Corresponding author:

\section{Vadood Razavilar}

Department of Food Hygiene, Science and Research Branch, Islamic Azad

University, Tehran, Iran

Email:

vazneh2245@gmail.com

Use your device to scan and read the article online

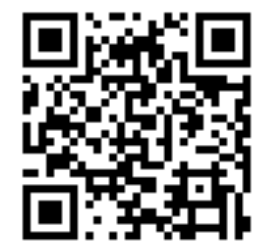

\section{Abstract}

Background and Aims: Microbial detoxification is one of the methods for eliminating of aflatoxins, including aflatoxin $\mathrm{M}_{1}$. Reports indicate that some strains of lactic acid bacteria family through surface adsorption of aflatoxin in their cellwall can be effective in removing them and as a primer culture. In this study, the ability of Bifidobacterium animalis and Lactobacillus delbrueckii in the adsorption of aflatoxin $\mathrm{M}_{1}$ in skim milk was assessed.

Materials and Methods: For this purpose, about $10^{8}$ and $10^{9} \mathrm{cfu} / \mathrm{ml}$ of B. animalis (Lactis) and $L$. delbrueckii (Blegaricus) were inoculated into skim milk without aflatoxin $\mathrm{M}_{1}$. Then, the samples were spiked by aflatoxin $M_{1}$ in concentrations of $0.25,0.5$ and $0.75 \mathrm{ng} / \mathrm{ml}$. The concentration of the aflatoxin reside in supernatant of milk samples after different storage times $(0.5,1,2$ and $24 \mathrm{~h})$ and temperatures of 4 and $37^{\circ} \mathrm{C}$ was measured by ELISA method, and the results were confirmed by HPLC.

Results: The results showed that the highest amount of aflatoxin $M_{1}$ removal was respectively related to B. animalis $(60 \pm 2.5 \%)$ with a concentration of $10^{8}$ cells/ $\mathrm{ml}$ and $L$. delbrueckii $(58.5 \pm$ $2.5 \%$ ) with a concentration of $10^{9}$ cells/ $\mathrm{ml}$ and a concentration of $0.5 \mathrm{ng} / \mathrm{ml}$ poison at $37^{\circ} \mathrm{C}$ for 30 minutes. By comparing the concentration of both bacteria, it also appeared that the $B$. animalis concentration at $37^{\circ} \mathrm{C}$ and $\mathrm{L}$. delbrueckii concentration at $4{ }^{\circ} \mathrm{C}$ were more effective. Also, the results indicate that the ability of bacteria to reduce the amount of poison in half an hour in milk samples with values of $0.75 \mathrm{ng} / \mathrm{ml}$ poison at $4^{\circ} \mathrm{C}$ and $0.5 \mathrm{ng} / \mathrm{ml}$ poison at $37^{\circ} \mathrm{C}$ is higher; but over time, contaminated milk at a concentration of $0.75 \mathrm{ng} / \mathrm{ml}$ poison compared to $0.5 \mathrm{ng} / \mathrm{ml}$ poison showed an increased amount of aflatoxin removal.

Calclusion: B. animalis and $L$. delbrueckii can act as two useful probiotics to reduce the harmful effects of aflatoxin $\mathrm{M}_{1}$.

Keywords: Aflatoxin $\mathrm{M}_{1}$, Probiotic, Detoxification, B. animalis, L. delberueckii, Skim milk

Received: 2018/11/16 Accepted: 2019/04/10 Available online: 2019/06/20

Copyright $\odot 2019$ Iranian Journal of Medical Microbiology. This is an open-access article distributed under the terms of the Creative Commons Attribution License (http://creativecommons.org/licenses/by/4.0), which permits unrestricted use, distribution, and reproduction in any medium, provided the original work is properly cited.

How to cite this article:

Namvarrad M, Razavilar V, Anvar S A A, Akbari Adargani B. Assessment of Lactobacillus Delbruekii and Bifidobacterium Animalis Abilities to Absorb Aflatoxin M1 from Milk. Iran J Med Microbiol. 2019; 13 (1) :44-55 


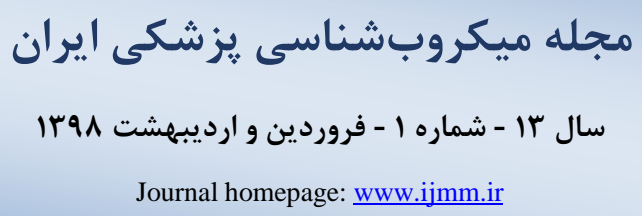

قابليت باكترىهاى Lactobacillus Delbrueckii و Bifidobacterium Animalis در جذب آخلاتوكسين M1 از شير

$$
\begin{aligned}
& \text { تلقيح دو نوع بروبيوتيك براى كاهش سميتزدايى از شير }
\end{aligned}
$$

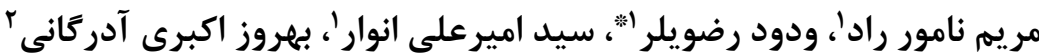

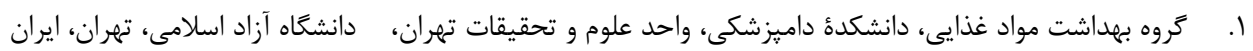

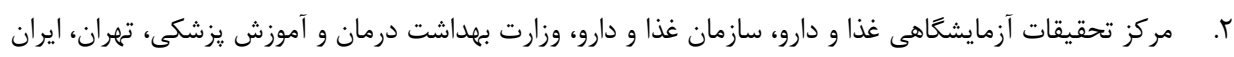

\section{جبكيده}

زمينه و هدف: توكسينزدايى ميكروبى يكى از روشهاى حذف آفلاتوكسينها از جمله آفلاتوكسين M1 محسوب ميىشود.

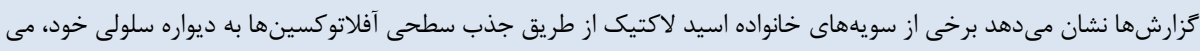
تواند در حذف آنها و به عنوان يك نوع كشت آغازگر مؤثر باشند. در اين تحقيق، توانايى باكترىهاى delbrueckii

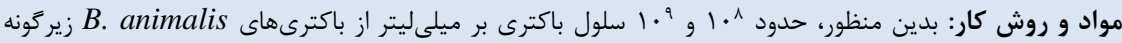

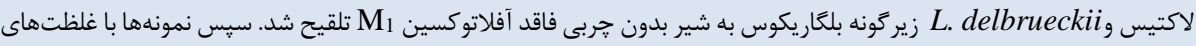

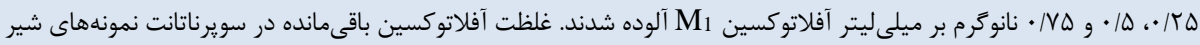

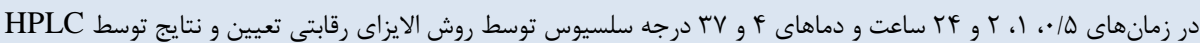
تأييد شد.

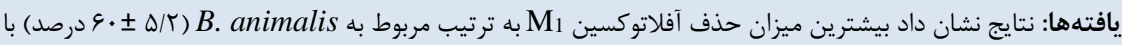

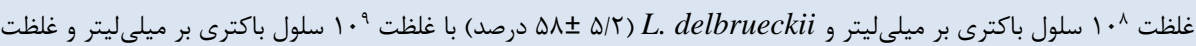

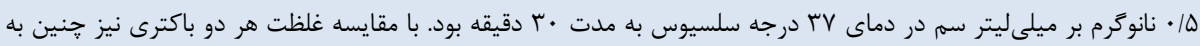

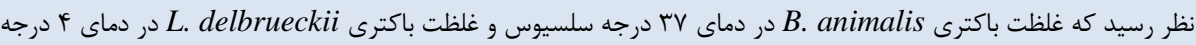

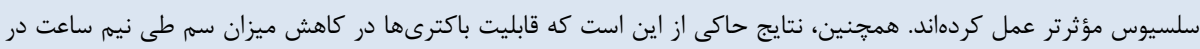

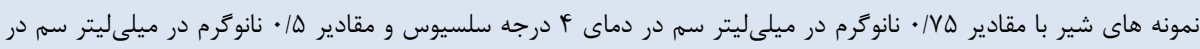

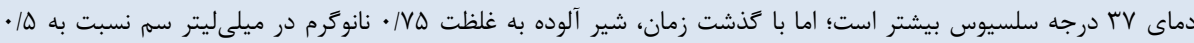

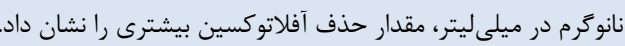

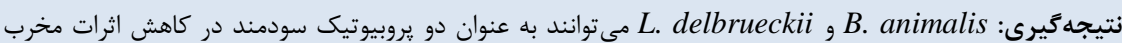

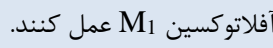

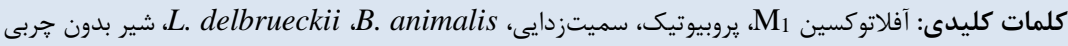

اطلاعات مقاله

تاريخٌجُ مقاله

دريافت:

يذيرش:|r||r||r||

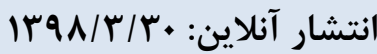

موضوع:

ميكروبيولوزى مواد غذايى

IJMM1398;13(1): 44-55

نويسندة مسئول:

ودود رضويلر

كروه بهداشت مواد غذايى، دانشكدة داميزشكى، واحد علوم و تحقيقات تهران، دانشكاه آزاد اسلامى، تهران، ايران

يست الكترونيك: vazneh2245@gmail.com

كيىرايت (C) مجله ميكروبشناسى بزشكى ايران: دسترسى آزاد؛ كبى بردارى، توزيع و نشر براى استفاده غيرتجارى با ذكر منبع آزاد

آفلاتو كسـينها از خطرناكترين مايكوتو كسـينها هسـتند و عمدتاً

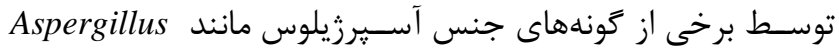
flavus Aspergillus parasiicus مى شوند (ץ). آفلاتوكسين ها ممكن است به طور مستقيم از طريق بلعيدن محصولات آلوده يا به طور غيرمستقيم تو سط مصرف مواد
مايكوتوكسينها، متابوليتهاى سمى توليدشده توسط قارج ها هسـتند كه به طور عمده توسـط قارجهاى سـايروفيت در حال

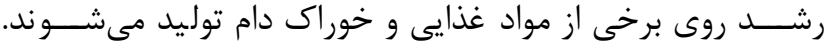

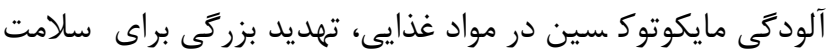

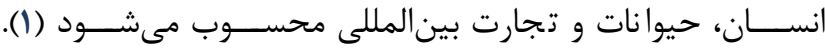


مى توانند به طور بالقوه براى سلامت انسان و دام خطر آفرين باشند،

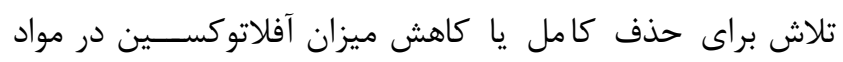
غذايى مضاف شده است (9).

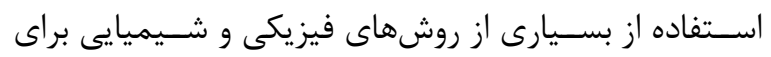

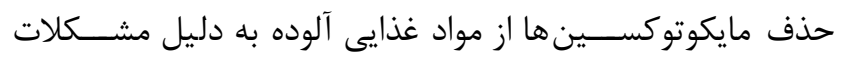

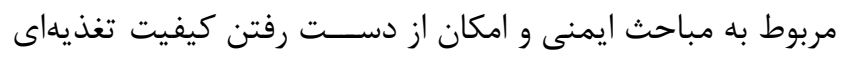

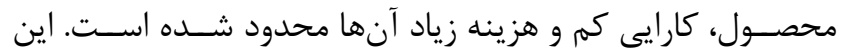

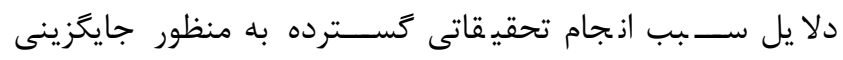

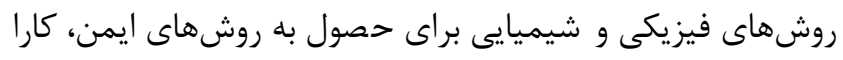

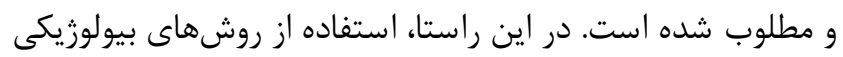

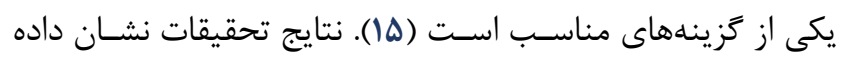

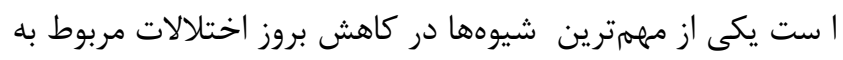

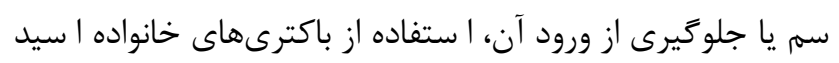

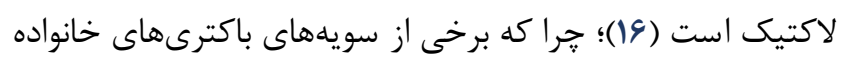

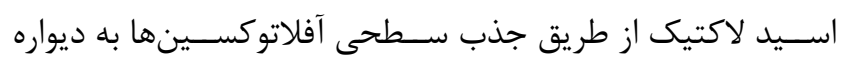

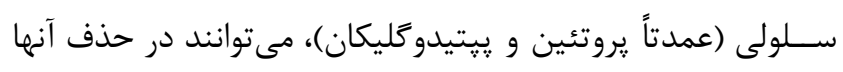

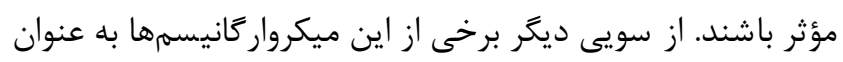

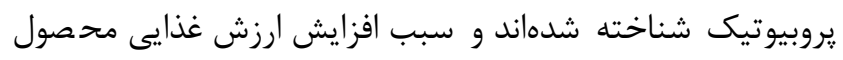

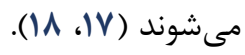

در بين ميكروار كانيسمهاى بروبيوتيك شناختهشده، دو سويه Bifidobacterium , Lactobacillus باكتريايى در زمينه توليد محصولات يروبيوتيك هستند و انتخاب

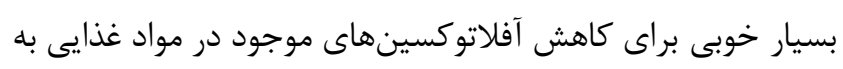

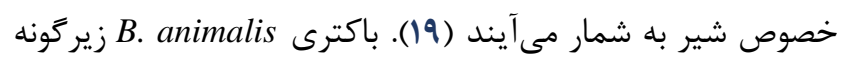

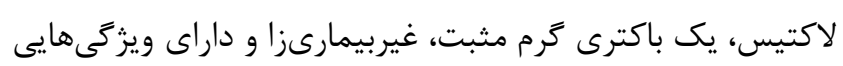

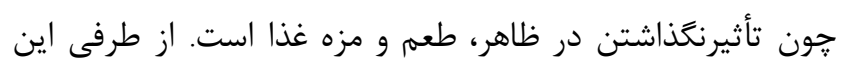

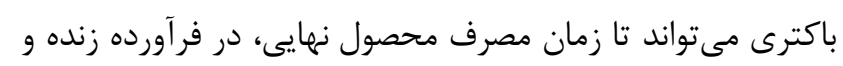

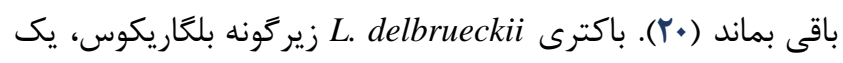

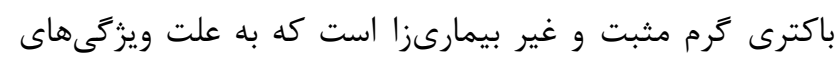

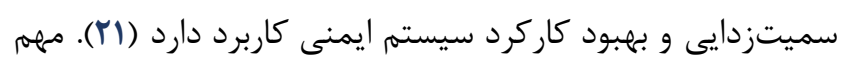

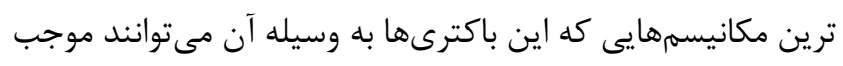

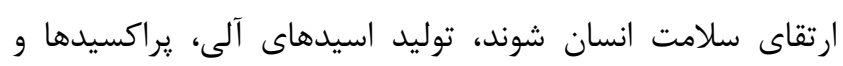

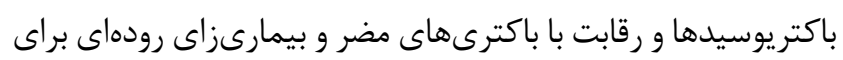

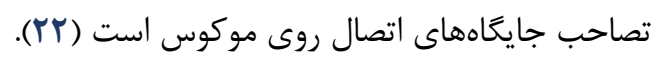

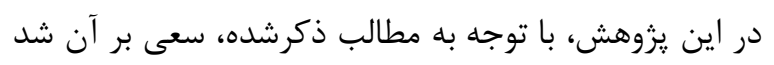

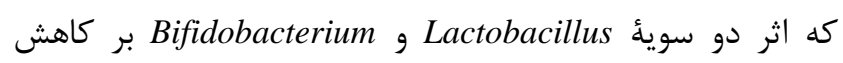

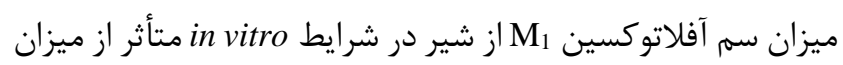
غلظت باكترى و سم، دما و زمان ارزيابى شود.
غذايى مشــتقشــده از مواد اوليه آلوده، مانند شــير و فرآوردههاى

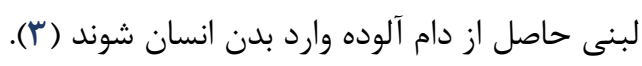

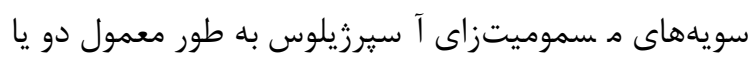

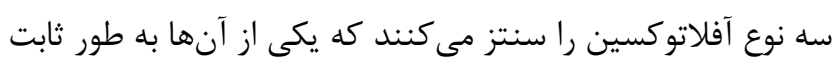

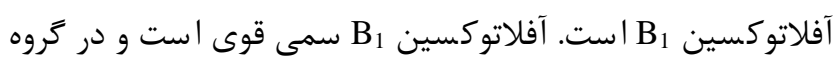

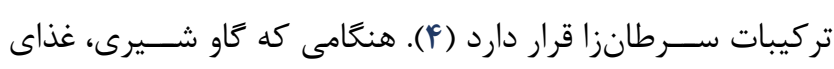

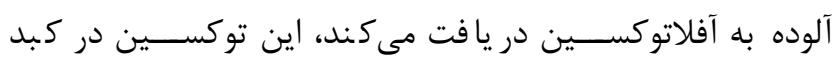

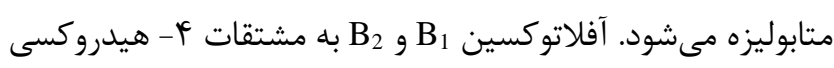

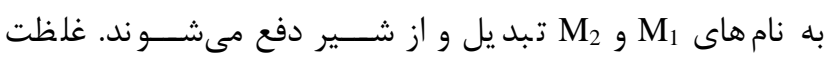

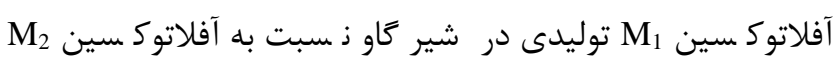

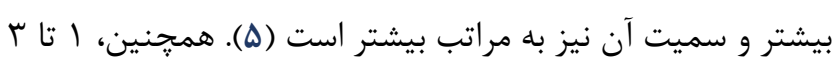

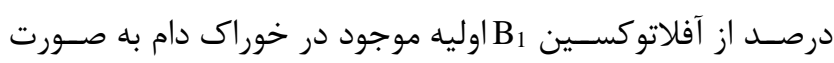

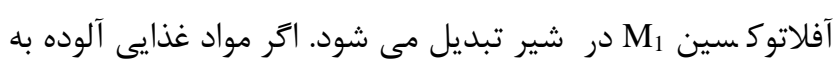

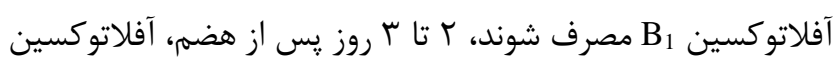

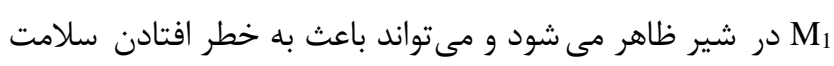

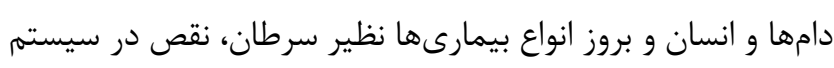

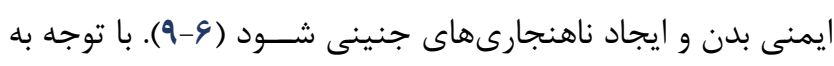

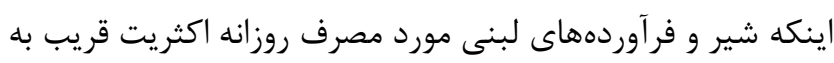

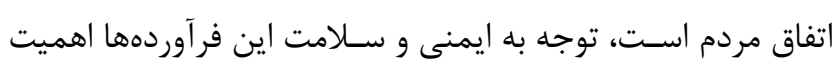

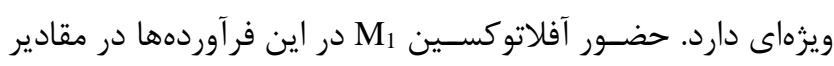
بيشتر از حد استاندارد، براى مصرف كننده مخاطرهآ آميز است.

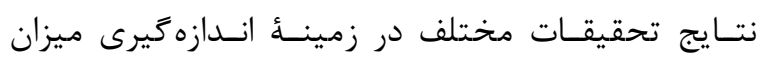

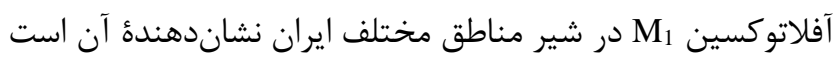

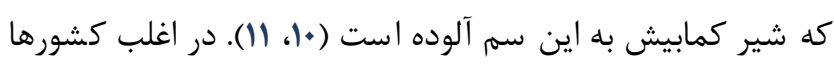

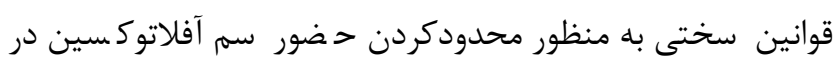

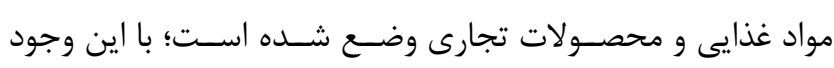

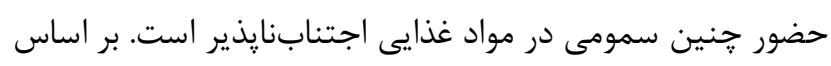
قوانين وضع شده تو سط سازمان غذا و داروى ايالات متحده آمريكا،

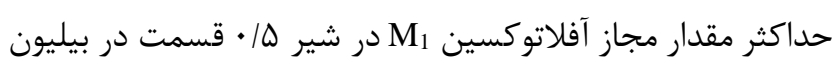

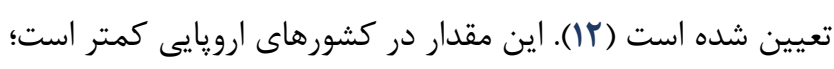

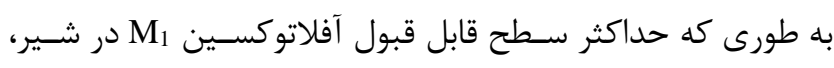

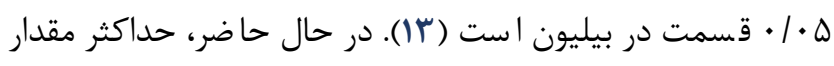

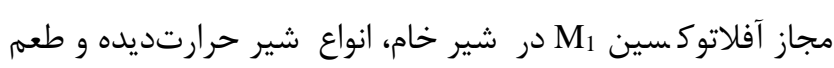

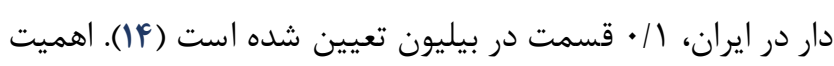

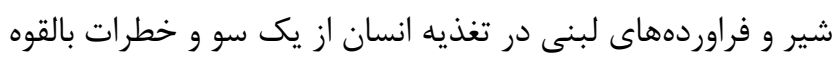

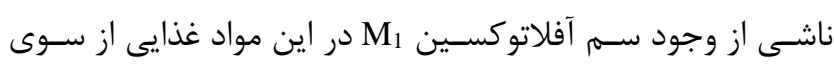

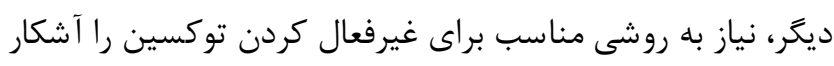

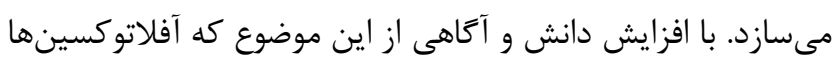




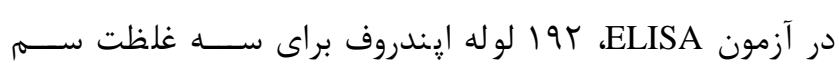

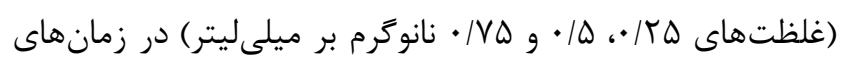

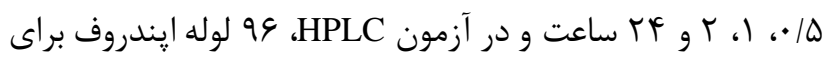

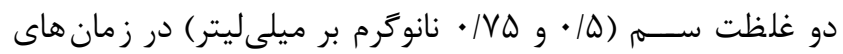

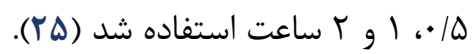

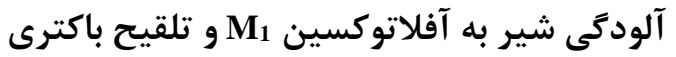

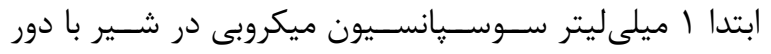

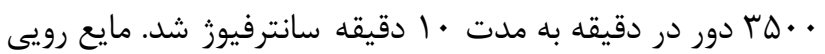

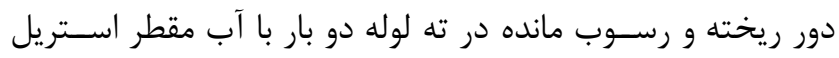

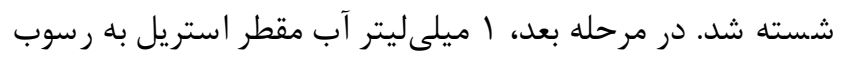

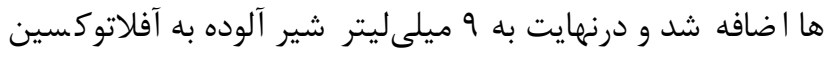

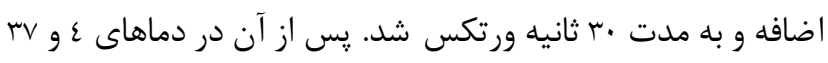

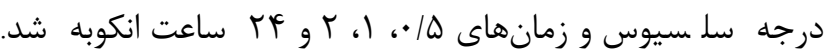

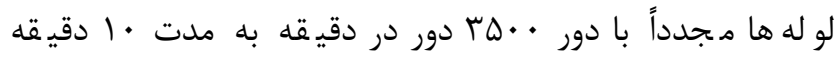

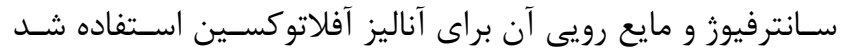

\section{(Spike) (آلودهكردن نمونه}

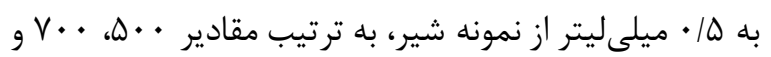

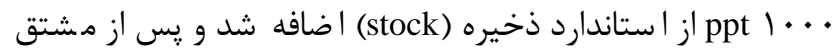

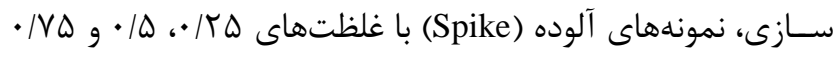

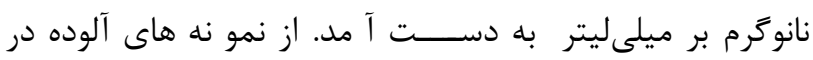
معتبرسازى روش، تعيين صحت و دقت استفاده شد.

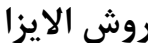

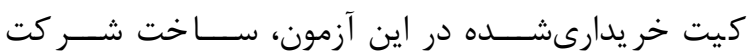

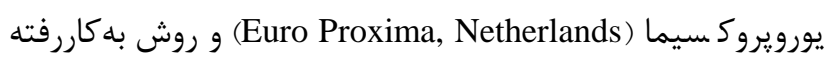

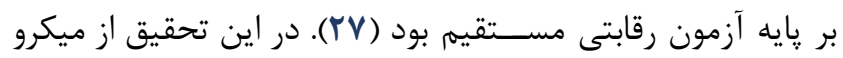
يليت و9 خانهاى استفاده شد كه به ترتيب در رديف اول از خاهك إنى

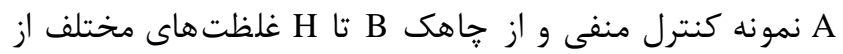

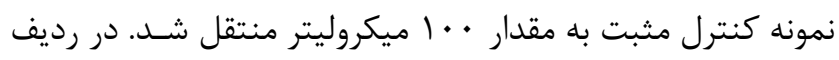
دوم از خاهك هاى ميكرويليت، نمونه هاى مورد آزمايش به ميزان

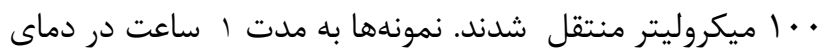
اتاق انكوبه شدند. سيس محلول داخل ميكرويليت تخليه و سه به بار با مايع شستو شوى كيت، شسته شد. ميكرويليت به شدت تكان اندان

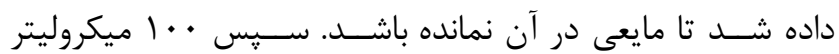

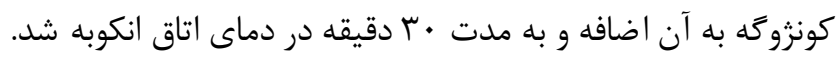

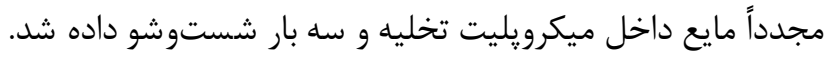

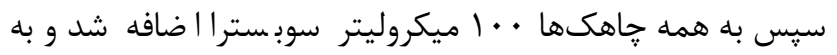

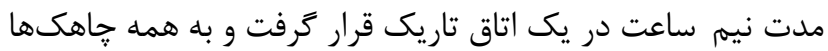

مواد و روشها

\section{تهيه ميكرواركانيسمها و آمادهسازى سوسيانسيون ميكروبى} ميكروار كانيسمهاى استفاده شده شامل B. animalis زيركونه

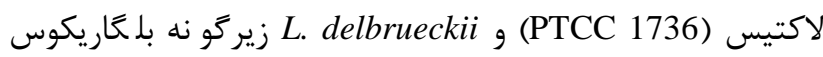

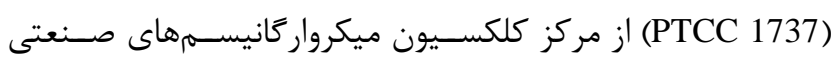

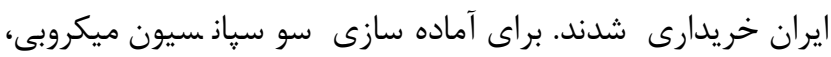

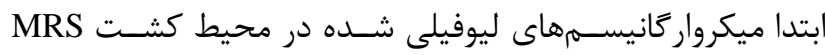

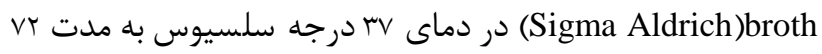

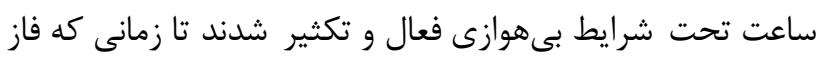

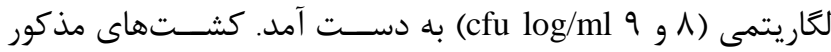

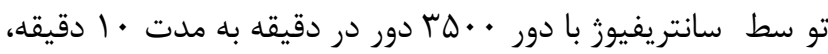

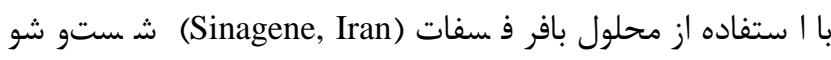
شدند و رسوب ميكروبى جداسازى شد. غلظت باكترىها با دستخاه ا سيكتروفتومتر (Ultrospec 2000, Pharmacia Biotech Inc) در

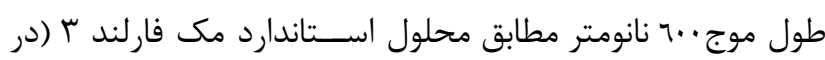

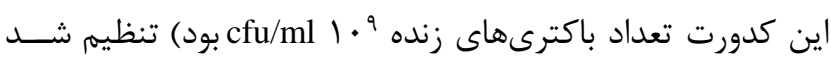

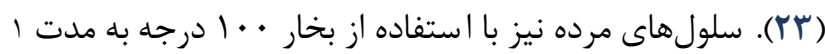

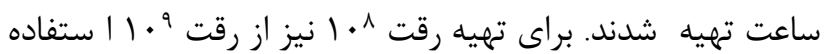
شد و به نسبت • ا:1 رقيقسازى صورت كرفت (YF).

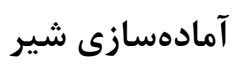

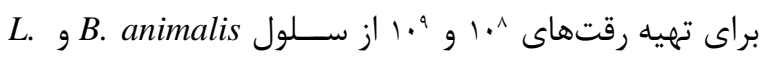
delbrueckii

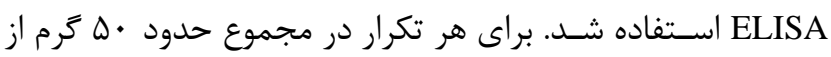

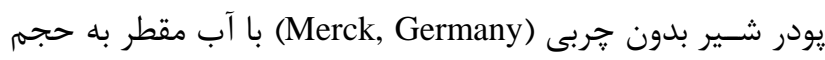

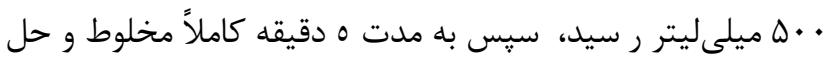

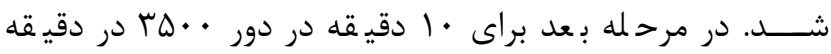

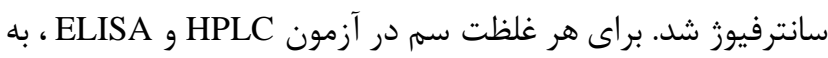

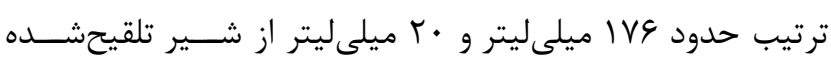

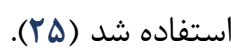

\section{M1 تهيه محلول آفلاتوكسين}

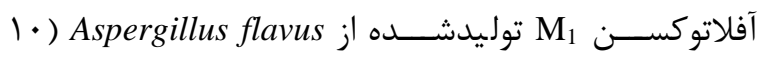

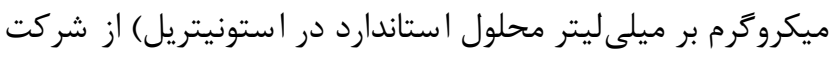

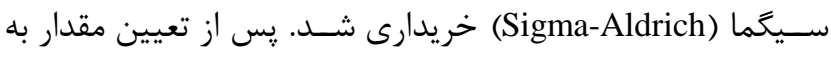

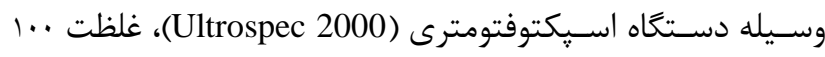

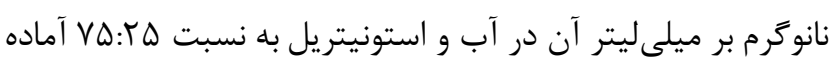

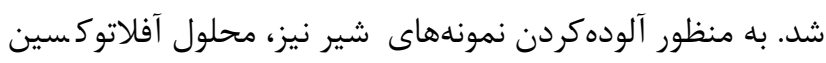

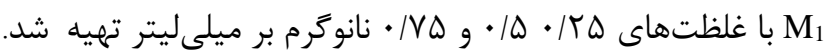




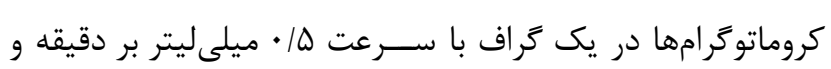

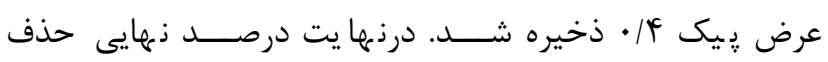

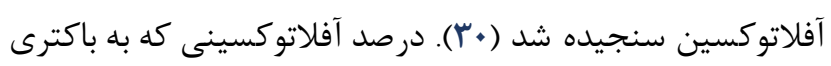

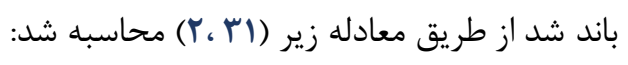

$$
\text { AFM=1 } 1 \text { AFM1 }
$$

\section{تجزيه و تحليل آمارى}

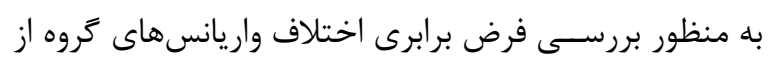

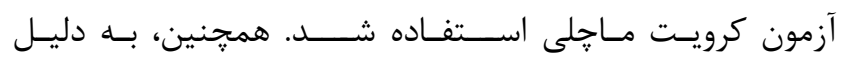

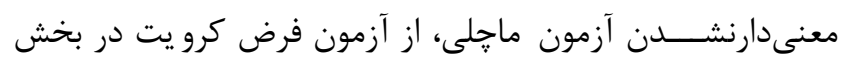

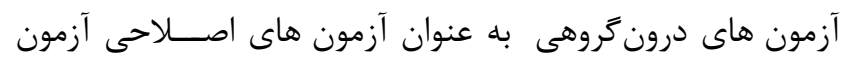

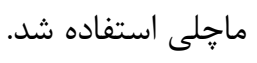
بافتهها

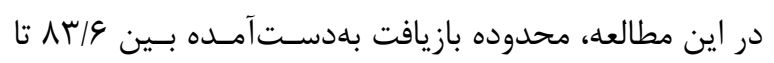

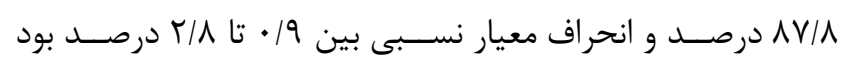

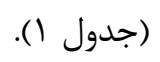

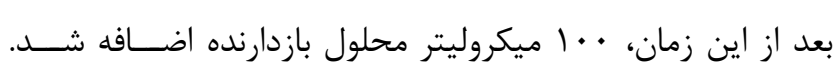

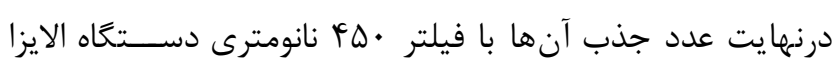
(Model EL × 808; Bio Tek USA)

\section{روش HPLC}

از دستغاه Breeze Seprations Module; Waters, ) HPLC كه مجهز به يمٍٍ داى دوتايى حلال و يك دريجه سوئيجى (USA

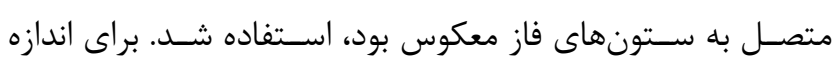

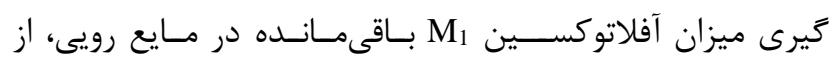

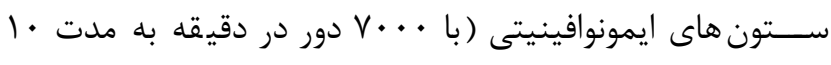

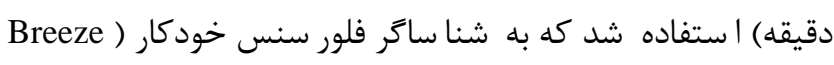

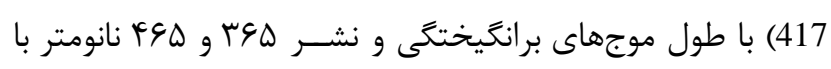
فاز معكوس (Performance RP-18Cmade of monolithicsilica)

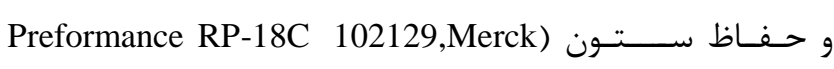
(endcapped guardcolumn )، مجهز بود. غلظت مربوطه با نرم افزار (تخار Empower

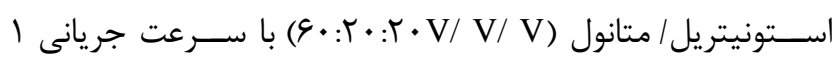

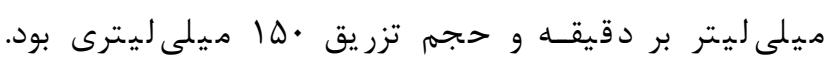

جدول ا. نتايج ارزيابى صحت روش بر اساس بازيافت (Recovery)

\begin{tabular}{|c|c|c|c|}
\hline pمt/ (Spike) نمونه هاى آلوده & نمونههاى آلوده بهدست آمده & ميانتين درصد بازيافت & درصد انحراف معيار \\
\hline$\Delta \cdots$ & $\cdot / r \Delta$ & $\Lambda \Upsilon / V \pm \cdot / q$ & $1 / 1$ \\
\hline$\vee \cdot$. & .10 & $\Lambda V / \Lambda \pm r / \mathcal{A}$ & $T / \Lambda$ \\
\hline $1 \ldots$ & $\cdot / V \Delta$ & $\Lambda \Delta / \varphi \pm \cdot / \Lambda$ & .19 \\
\hline
\end{tabular}

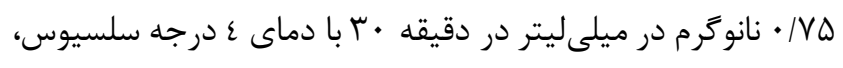

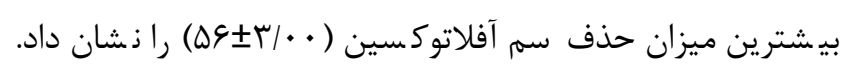

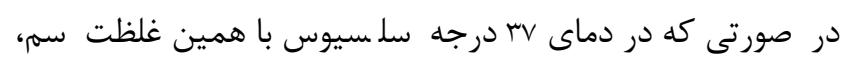
بي شترين در صد حذف سم آفلاتوكسين در مقدار • /

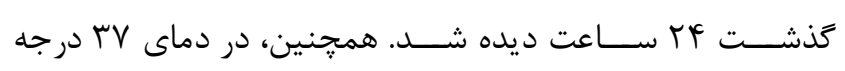

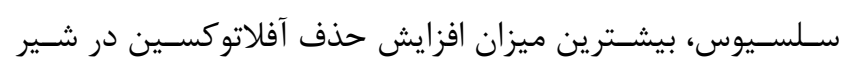

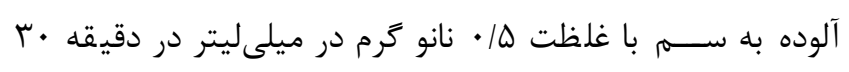

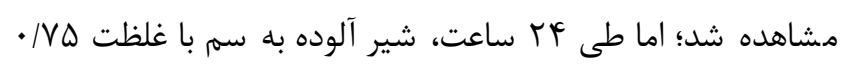

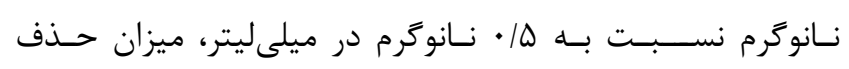
آفلاتوكسين بيشترى را نشان داد. نسان

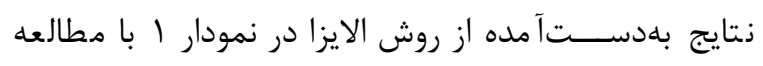

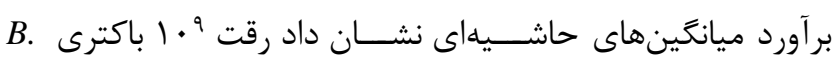
animalis

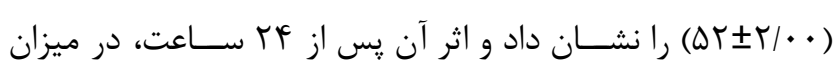

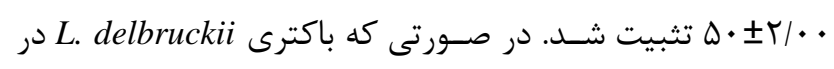
رقت 9 • ا در دقيقه •ج بيشـترين ميزان حذف سـهم آفلاتوكسـين

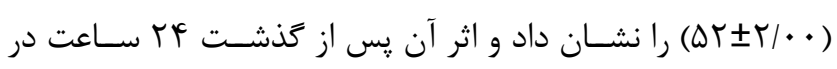

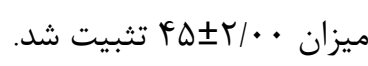
با مطالعه برآورد ميانخينهاى حا شيهاى اثرات متقابل غلظت تُبن سم، دما، زمان (نمودار () مـشخص شد شير شير آلوده با غلظت سم 

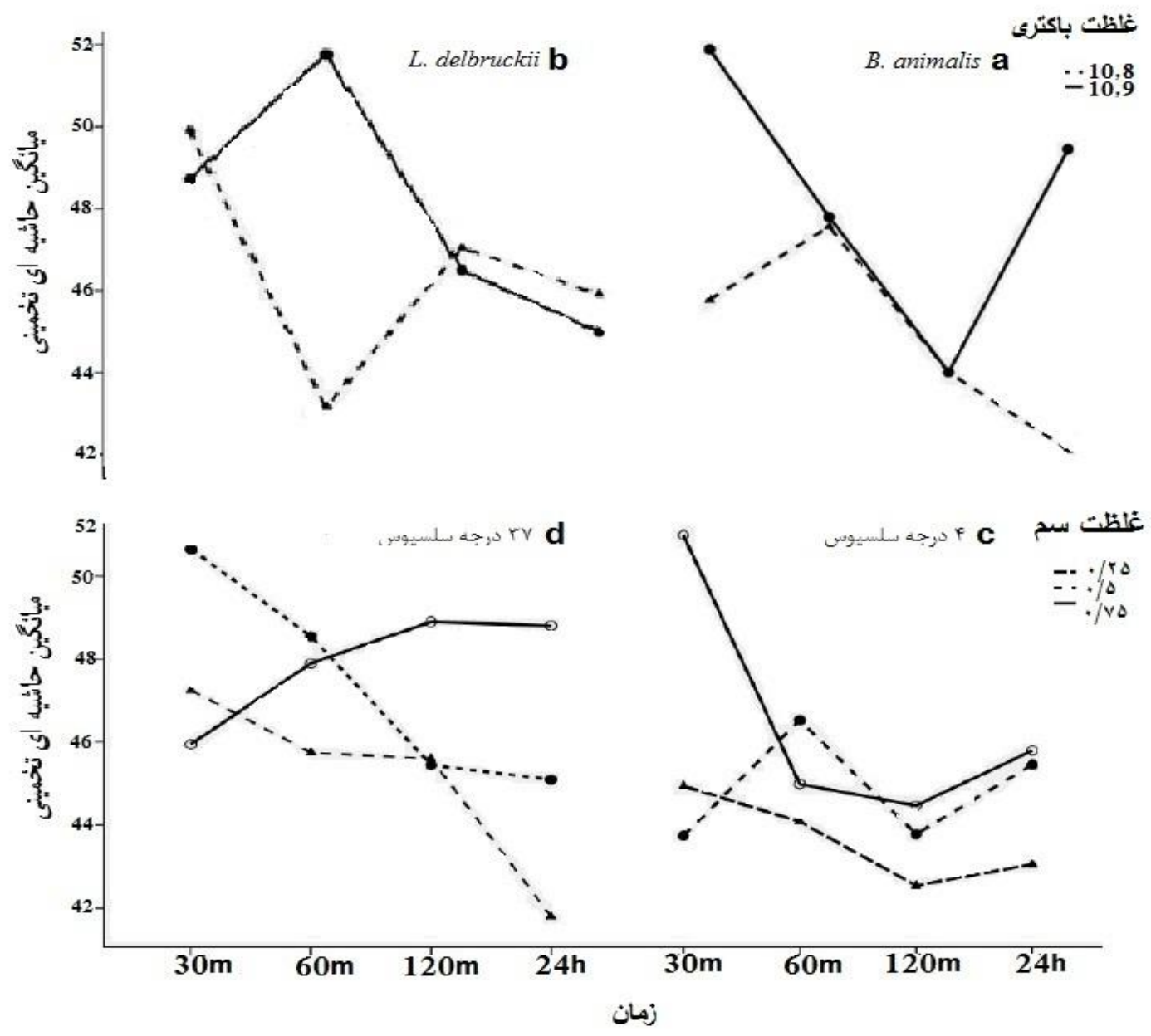

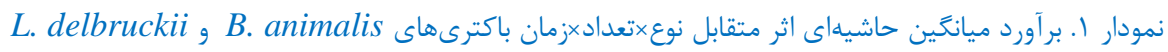

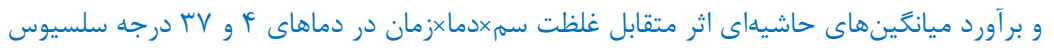

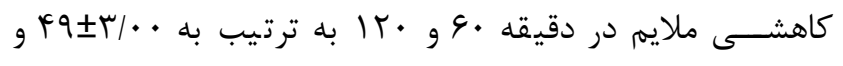
• • • •

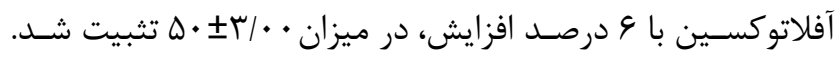

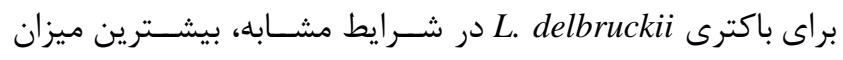

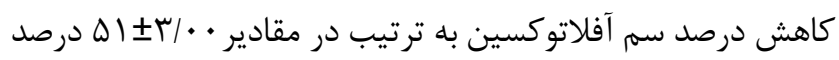
در دقيقه ·r، · · / ·

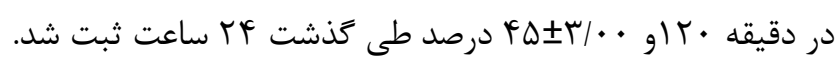

از سويى ديخر، با مطالعه برآورد ميانگينهاى حاشيهاى اثرات متقابل نوع باكترى، تعداد باكترى، دما، زمان (نمودار بار) و مقايسـهـ

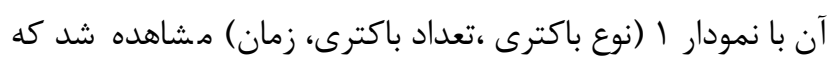

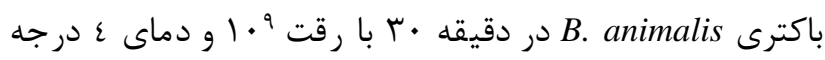

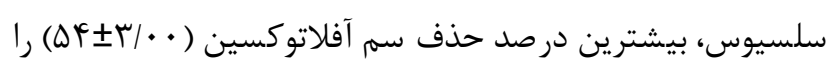

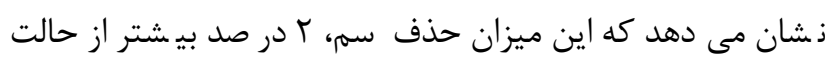
دخالتنكردن دما در سنجش دادهها در زمان مشابه بود، سيس بـ ديا 


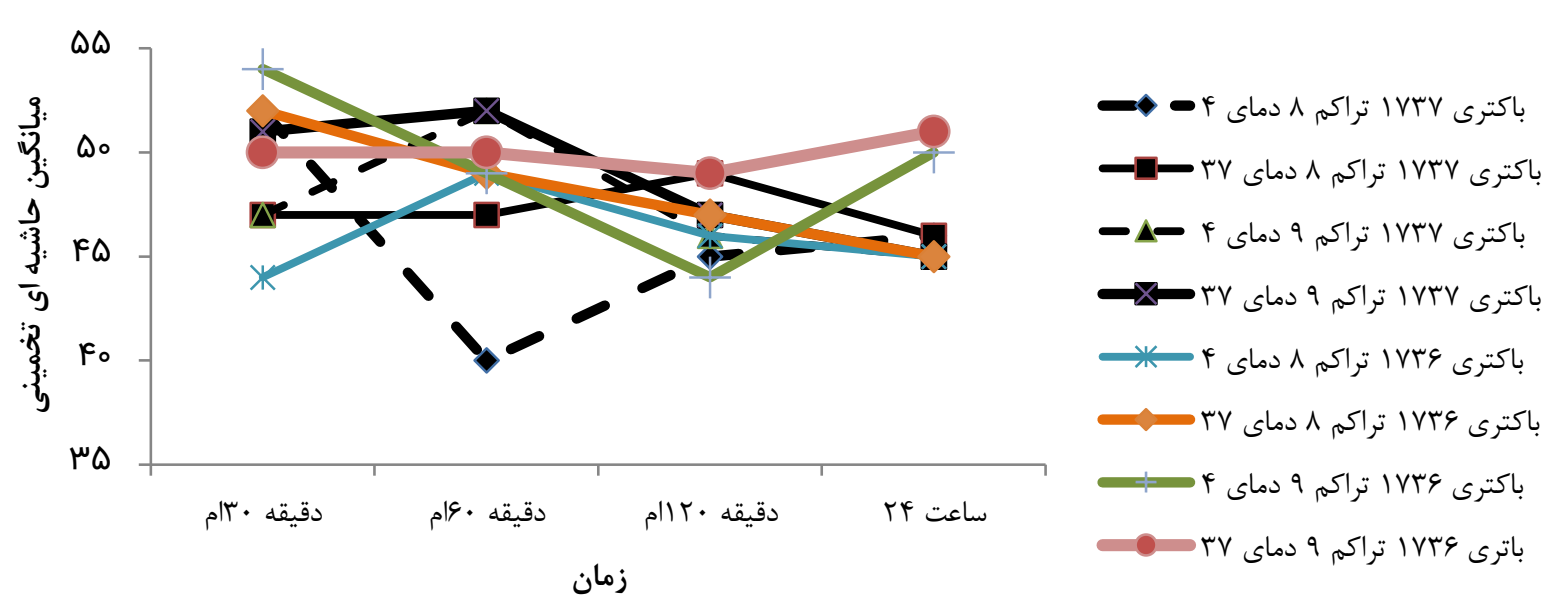

L. delbruckii, B. animalis نمودار r. برآورد ميانكَين حاشيهاى اثر متقابل نوع باكترى×غلظت باكترى×دما×زمان

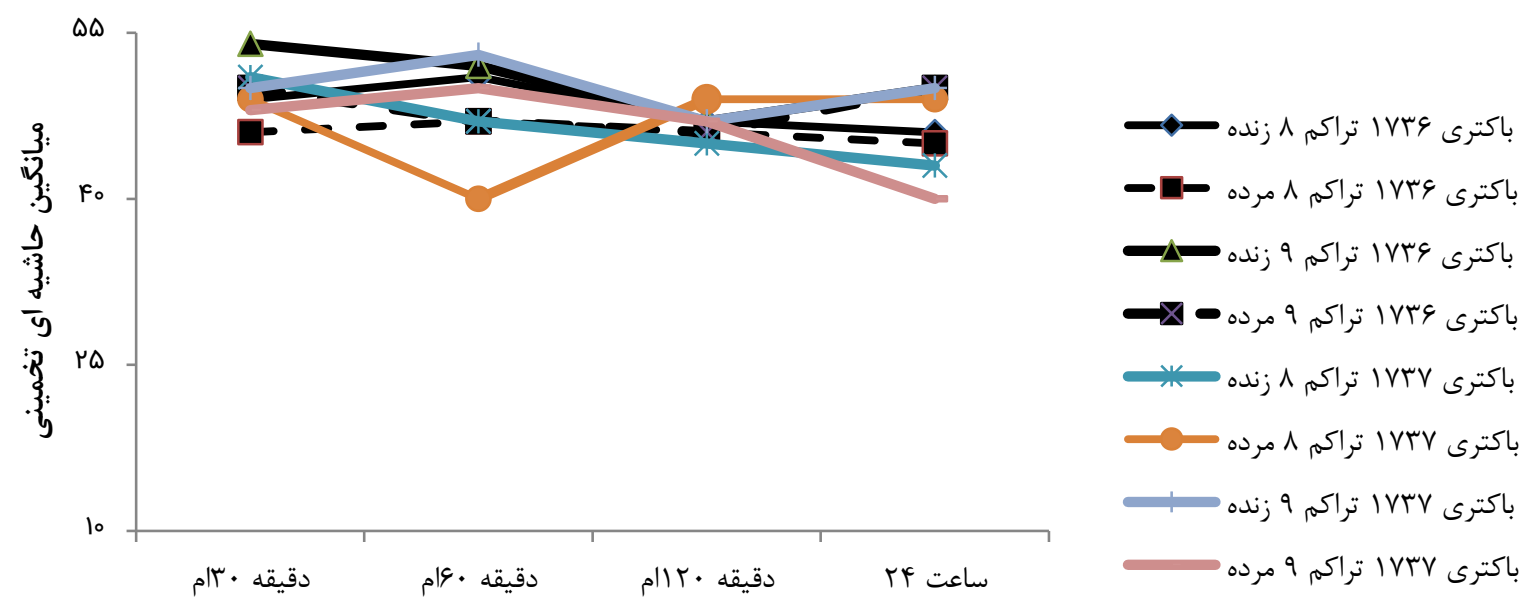

زمان

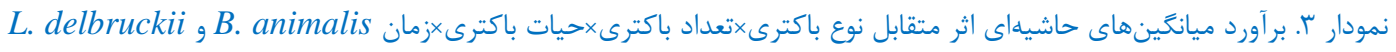

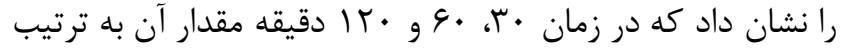

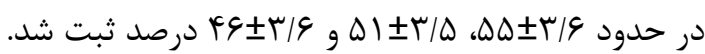

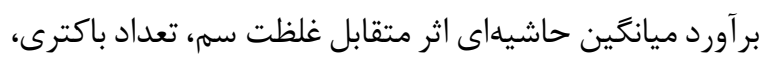

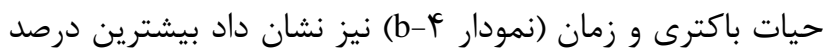

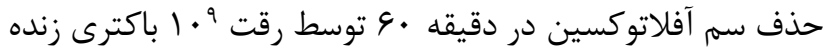

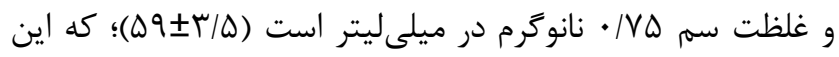

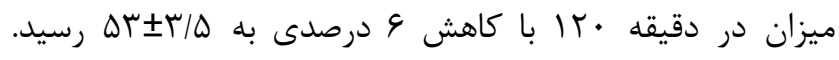

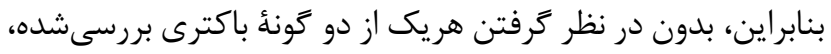

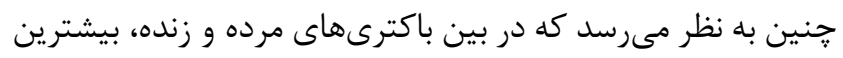

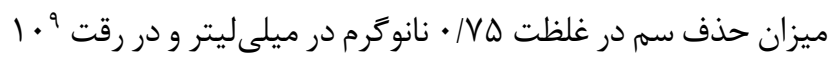

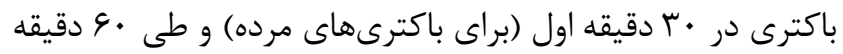

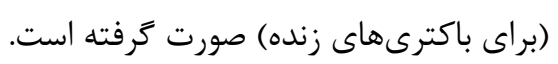

در بررسـى اثرات متقابل نوع باكترى، تعداد باكترى، حيات

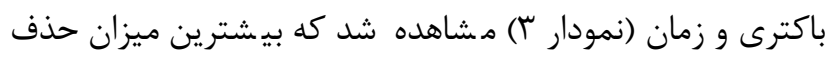

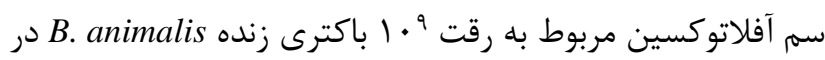

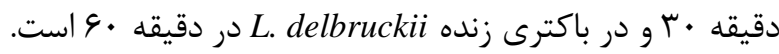

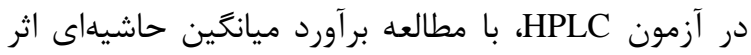

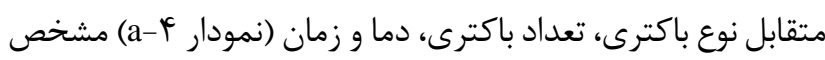

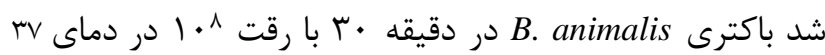
درجه سلسيوس بيشترين ميزان حدف سم آفلاتوكسين را نشان داد

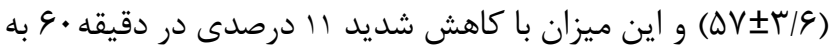
د/ه/

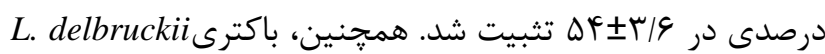

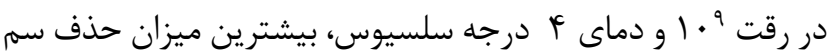




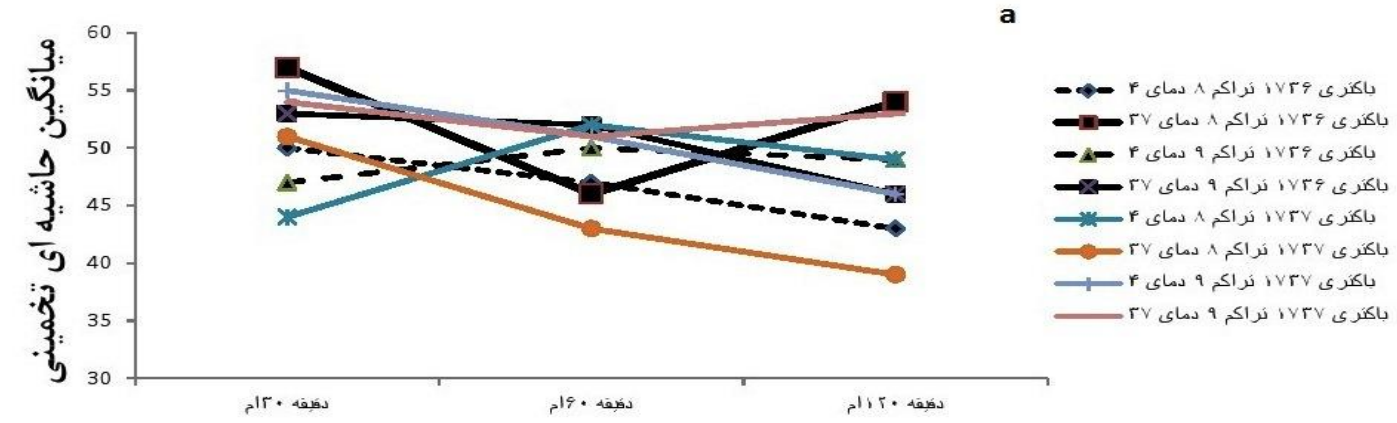

b

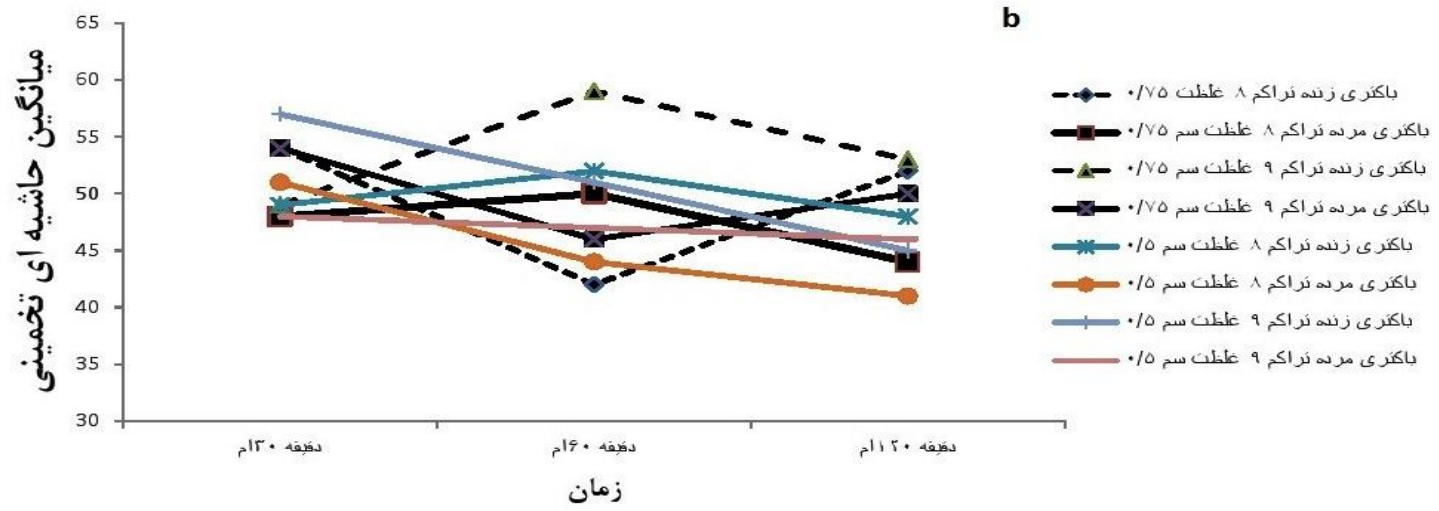

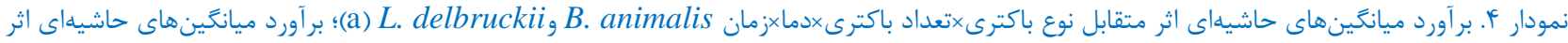

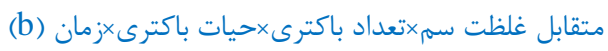
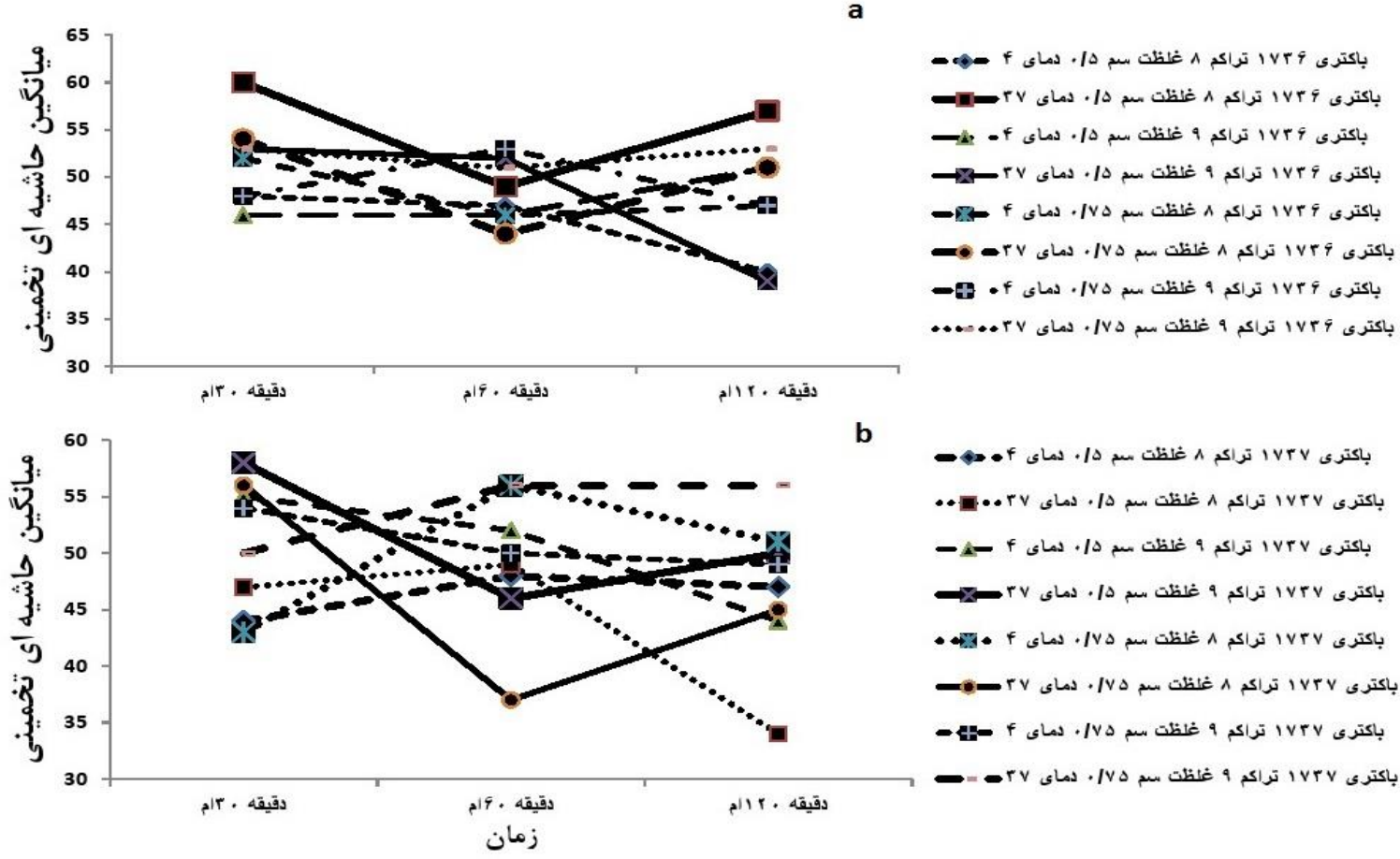

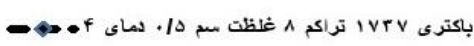

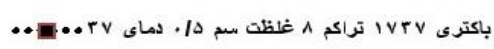

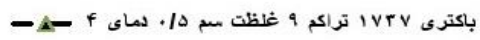

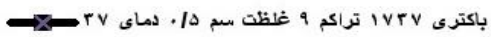

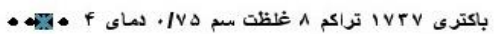

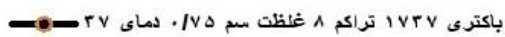

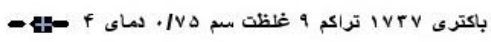
باكترى ivrv نمودار ه. برآورد ميانكينهاى حاشيهاى اثر متقابل نوع باكترى×تعداد باكترى×غلظت سم×دما×زمان (b) L. delbruckii (a) B. animalis

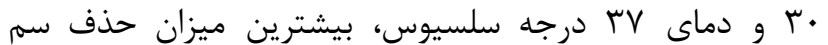

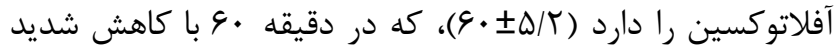

نتايج حاصل از نمودار ه نشان داد باكترى B. animalis رقت ^ • ا و محيط سم با غلظت ه| • نانو گرم در ميلىليتر، در دقيقه 
به cfu/ml ^• 1، توانمندى باكترى B. animalis در كاهش ســم

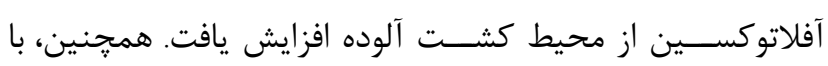

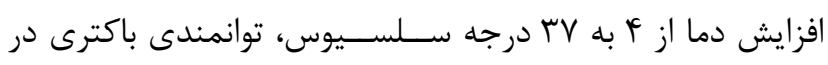

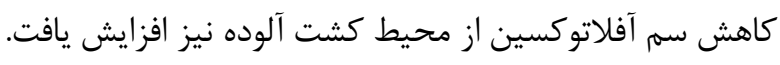

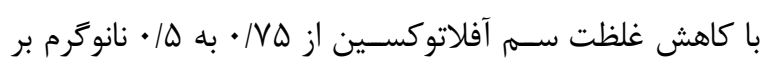

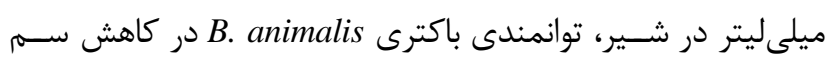

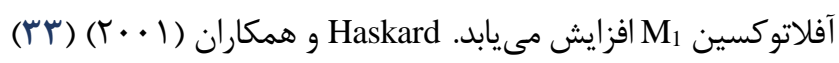
ززارش كردند حذف آفلاتوكســين شــديداً به نوع باكترى (ديواره

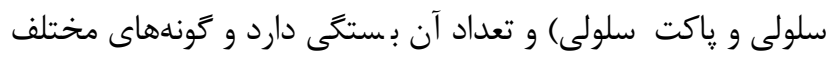

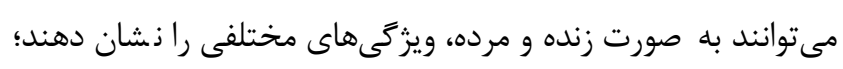
به طورى كه باكترىهاى مرده در اغلب گونهها، توانمندى بيشـترى

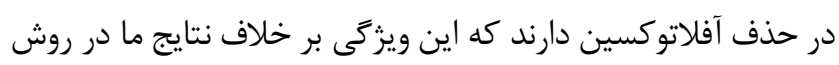
HPLC باكترىهاى كرم مثبت ذسبت به باكترىهاى گرم منفى اثر بيشترى

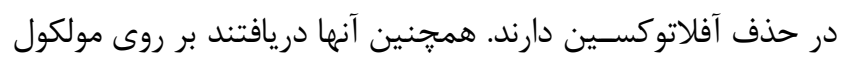
آفلاتوكسين M1 يك گروه هيدروكسيل اضافه وجود دارد كه باعث افزايش قطبيت و حلاليت بيشتر در محلول مىشود و كاهى مى در روشهايى با دقت كمتر، مـ شكل ايجاد كند. ش شايد يكى از دلايل

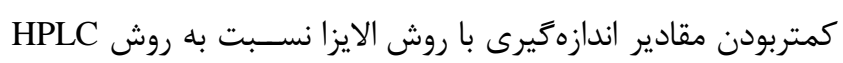
همين موضوع باشد. در اين مطالعه، ميزان دقت شمارش حذف آفلاتوك سين در روش الايزا ذسبت به روش HPLC كمتر بود. اين مو ضوع مىتواند

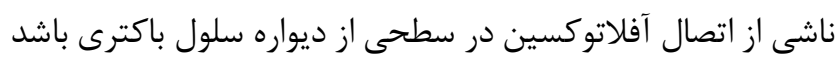

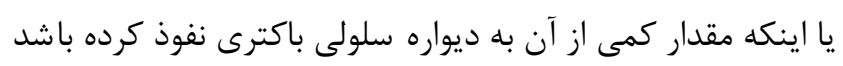
كه قابل شنا سايى تو سط آنتىبادى نبوده ا ست (هَr). -Serrano Mino

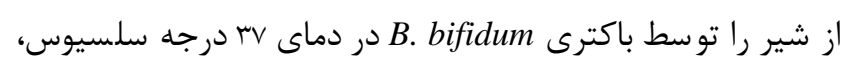

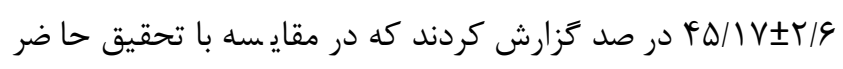

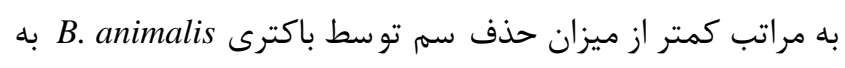

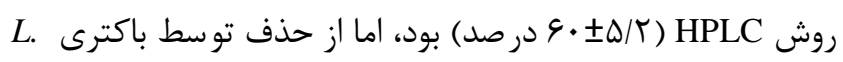
Elbruecii Elsanhoty

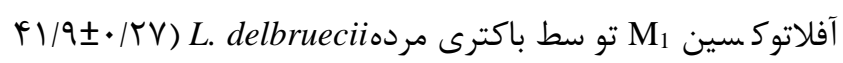

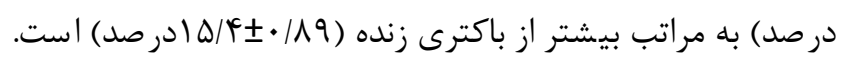
Bovo

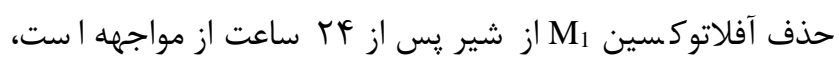
اما اختلاف معنى دارى (P-Value>0.05) بين باكترى زنده و مرده B. وجود نداشـــ L. delbruecii
| 1 درصدى به توجه \ درصدى در ميزان درصد حذف طى دوره تحقيق معادل بر اساس نمودار b-b نيز بيشترين كاهش حذف سم آفلاتوكسين

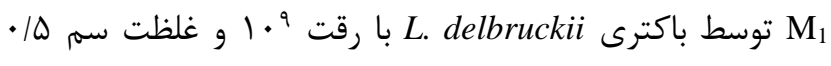

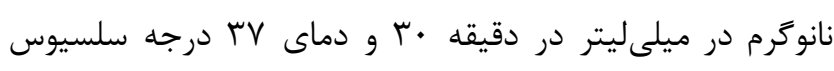

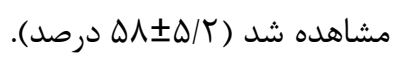

$$
\text { بحث و نتيجه تَيرى }
$$

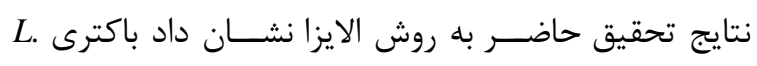
delbruecii

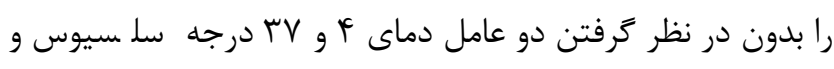

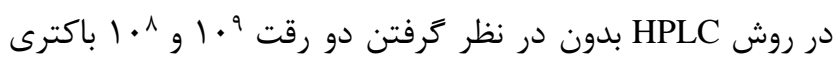
و يا دماهاى مذكور، به طور قابل توجهى حذف كند. با توجه به دون

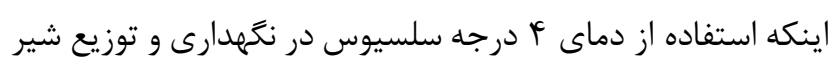
كاربرد فراوانى دارد، بررسى حذف آفلاتوكسين M1 به روش زشان داد باكترى L. delbruecii تحت تأثير غلظت سم و در دماى درى درى

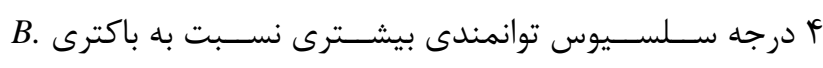
Bovo براى حذف آفلاتوكسـين Mimalis

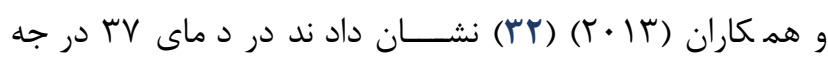

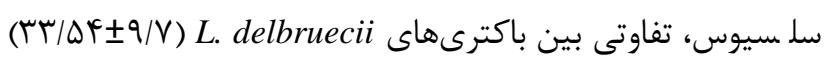

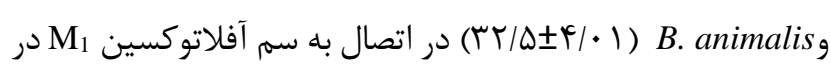

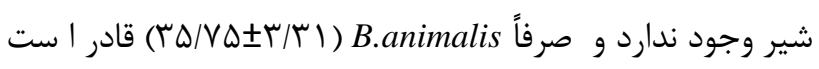

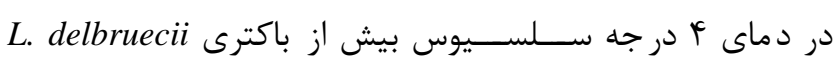

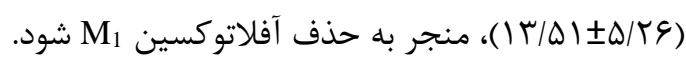
Corassin حذف آفلاتوكســين M.animalis به و

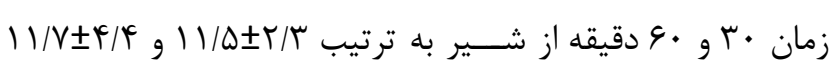

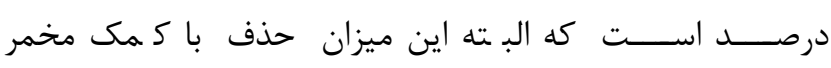
Saccharomyces cerevisiae

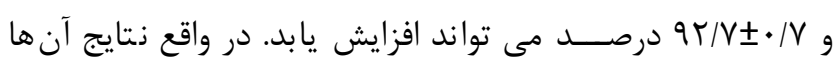
ز شان داد عوامل محيطى نظير دما، غلظت سمى و تعداد باكترى به ديه

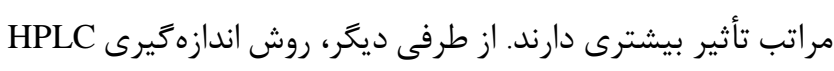
، درصد حجم بيشترى از كاهش سم را نسبت به روش الايزا نشان

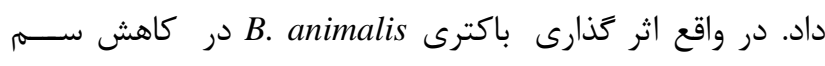

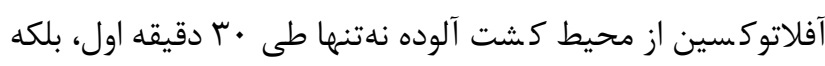

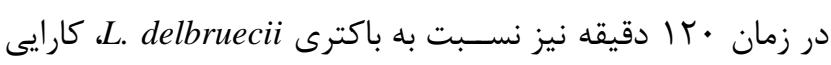

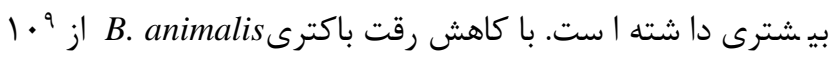




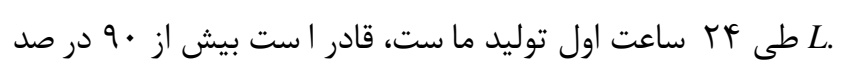

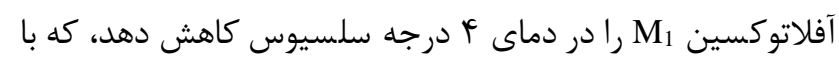

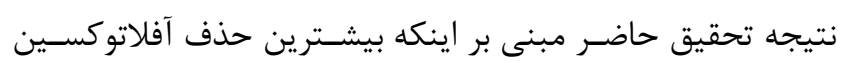

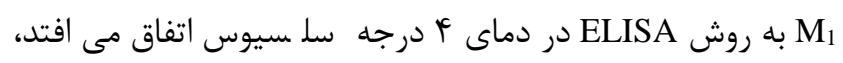

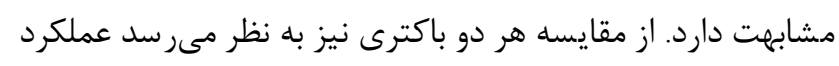

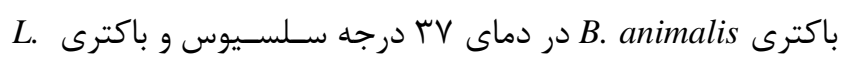

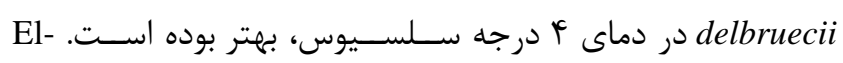
Nezami

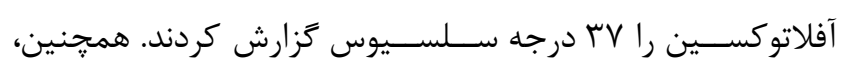
Elgerbi

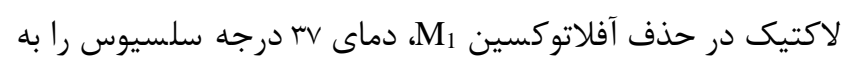
عنوان دماى بهتر معرفى كردند.

با توجه به خطرات بالقوه ناشى از آلودكى با بآنلاتو كسين

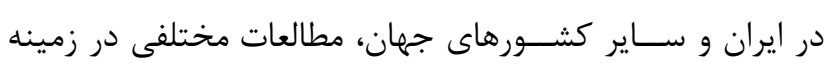

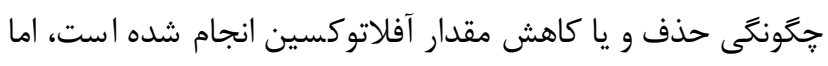

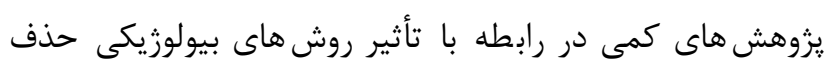

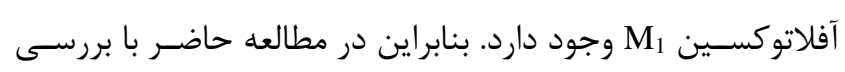

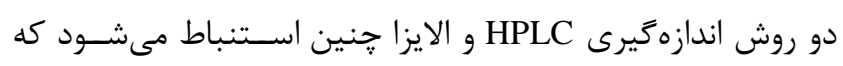

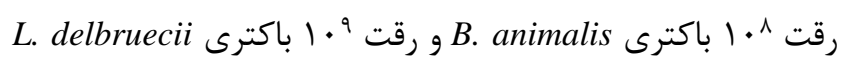

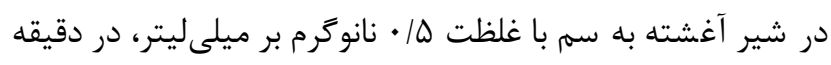

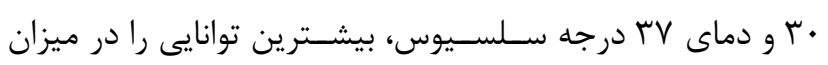

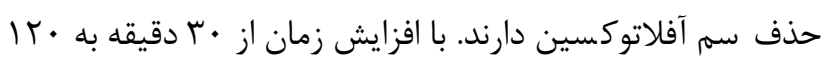

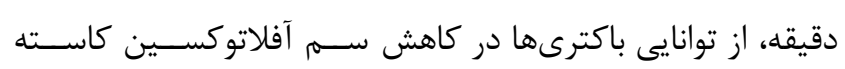

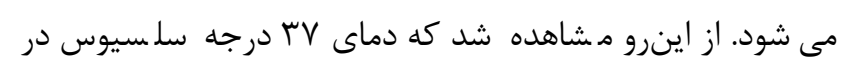

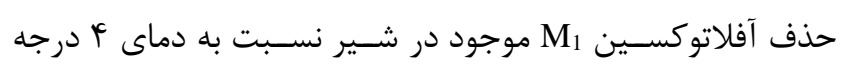

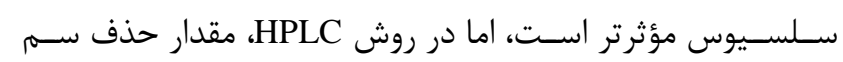

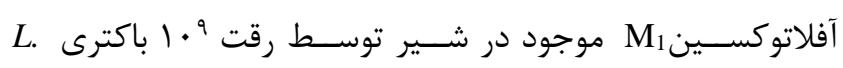
delbruecii

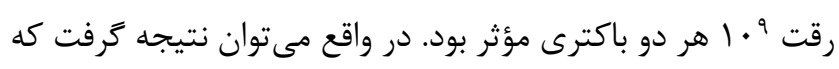

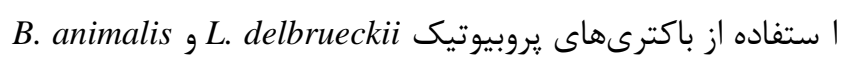

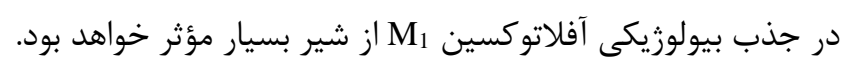

\section{سياسگَزارى}

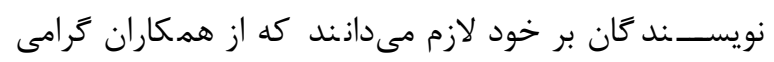

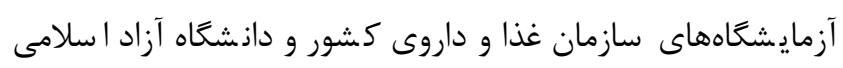
واحد علوم و تحقيقات تهران كمال تشكر را داشته باشند.

$$
\text { تعارض منافع }
$$

نويسندًان هيجَّونه تعارض منافعى ندارند. animalis

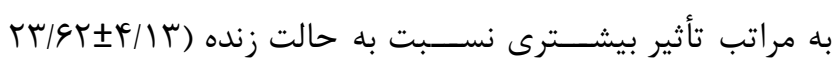

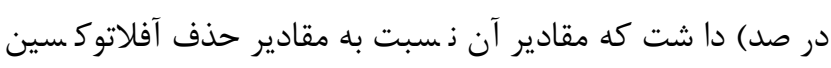

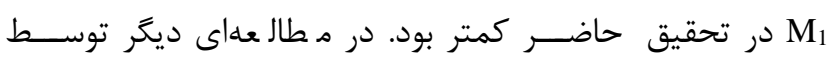

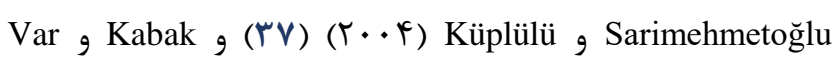

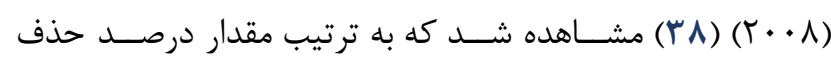

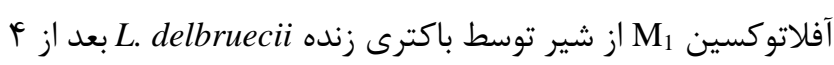

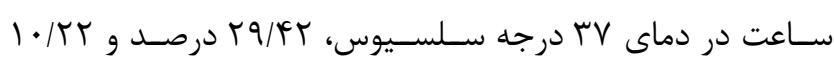

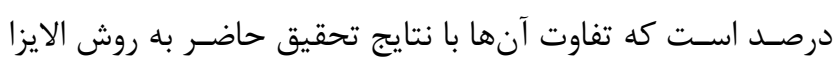

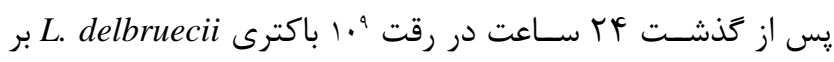
ميلى ليتر، قابل تامل بود.

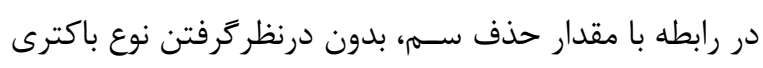

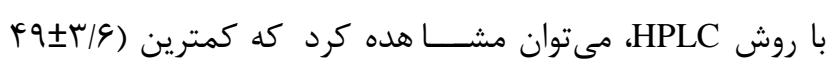

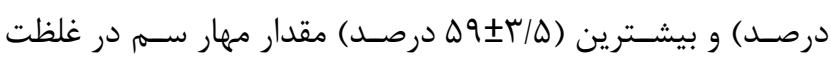

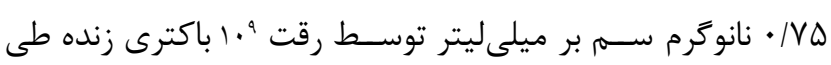

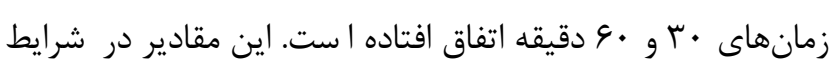

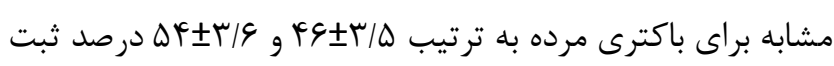

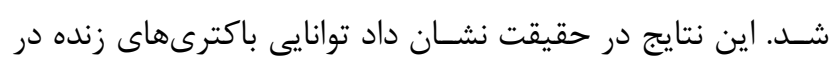

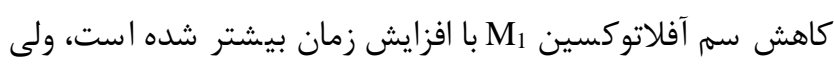

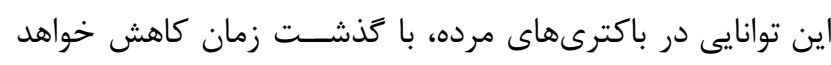

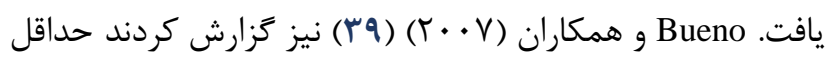

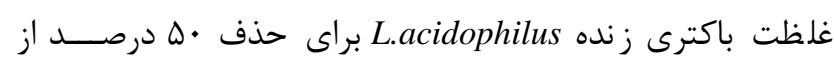

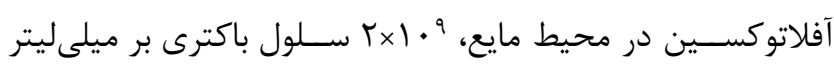

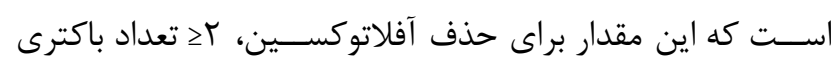
B.animalis

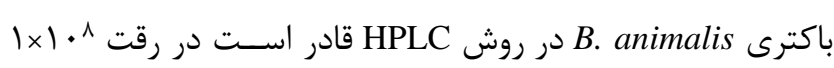

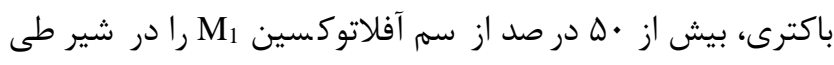

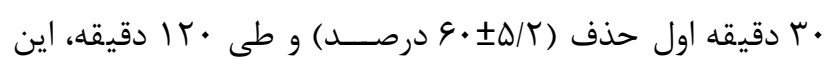

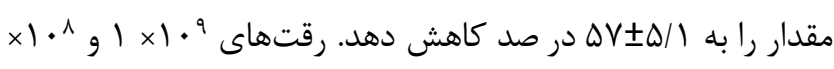

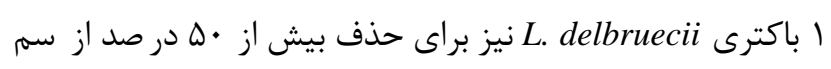

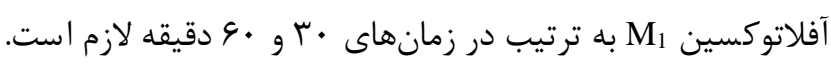

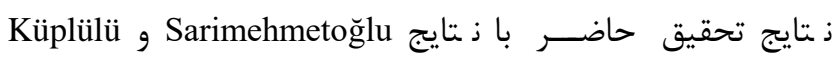

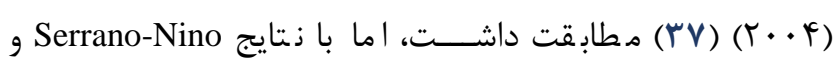

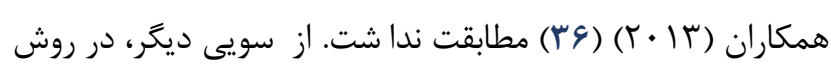

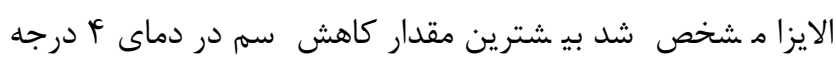

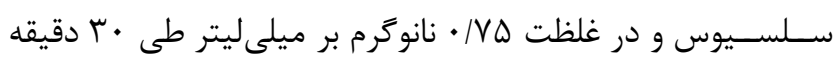

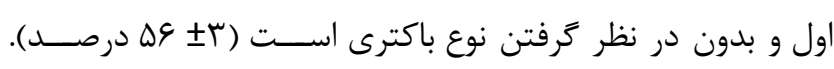
acidophilus و همكاران (1) Adibpour 


\section{References}

1. Binder EM, Tan LM, Chin LJ, Handl J, Richard J. Worldwide Occurrences of Mycotoxins in Commodities, Feeds and Feed Ingredients. Animal Feed Sci Tech. 2007; 137: 265-282.

2. Corassin $\mathrm{CH}$, Bovo F, Rosim RE, Oliveira CAF. Efficiency of Saccharomyces Cerevisiae and Lactic Acid Bacteria Strains to Bind Aflatoxin $M_{1}$ in UHT Skim Milk. Food Control. 2013; 31(1):80-83.

3. Caloni F, Stammati A, Frigge G, De-Angelis I. Aflatoxin $\mathrm{M}_{1}$ Absorption and Cytotoxicity on Human Intestinal In Vitro Model. Toxicon. 2006; 47:409-415.

4. International Agency for Research on Cancer. IARC Monograph on the Evaluation of Carcinogenic Risk to Humans, Vol 82. International Agency for Research on Cancer-World Health Organization, Lyon; 2002.

5. Rahimi E, Bonyadian M, Rafei M, Kazemeini HR. Occurrence of Aflatoxin $M_{1}$ in Raw Milk of Five Dairy Species in Ahvaz, Iran. Food and Chemical Toxicology. 2010; 48: 129-131.

6. Mirdamadi S, Rajabi A, Aziz Mohseni F, Momen B. Lactic Acid Production by Lactobacillus Strains. Iranian J Nut Sci Food Tech. 2007; 2(3):57-64.

7. Ardic M, Karakaya Y, Atasever M, Durmaz $H$. Determination of Aflatoxin B1 Levels in Deep-Red Ground Pepper (isot) Using Immune Affinity Column Combined With ELISA. Food and Chemical Toxicology. 2008; 46:1596-1599.

8. Masoero F, Gallo A, Diaz D, Piva G, Moschini M. Effects of the Procedure of Inclusion of a Sequestering Agent in the Total Mixed Ration on Proportional Aflatoxin $\mathrm{M}_{1}$ Excretion Into Milk of Lactating Dairy Cows. Animal Feed Sci Tech. 2009; 150: 34-45.

9. Womack ED, Sparks DL, Brown AE. Aflatoxin $M_{1}$ in Milk and Milk Products: A Short Review. World Mycotoxin J. 2016; 9(2):305-315.

10. Ersali A, Baho-Aldini Baigi F, Ghasemi R. Transmission of Aflatoxins from Animal Feeds to Raw and Pasteurized Milk in Shiraz City and its Suburbs. JSSU. 2009; 17(3):175-183.

11. Jafari R. Evaluation of Aflatoxin $\mathbf{M}_{1}$ Contamination in Delivery Milk and Pasteurized Milk Produced by Regional Milk Factory of East Azarbaijan. Master's Degree in Nutrition, Tabriz University of Medical Sciences; 2009.

12. Nakhaei A, Afzali N, Hosseini Vashan S J, Karimi Torshizi M A. Protective Effect of Egg Yolk Immunoglobulin (IgY) Against Aflatoxin on Blood Parameters, Ileum Morphometry and Hepatocytes'
Histopathology of Broiler Chickens Fed Aflatoxin B1. Iran J Med Microbiol. 2018; 12 (3) :199-207

13. Mishra HN, Das C. A Review on Biological Control and Metabolism of Aflatoxin. Critical Reviews in Food Sci Nut. 2003; 43(3):245-264.

14. Institute of Standards and Industrial Research of Iran. Human Feed-Animal Maximum Tolerance of Mycotoxins (Amendment No. 1), Standard No. 92. $2^{\text {nd }}$ ed. Tehran; 2010.

15. Kabak B, Dobson ADW, Var I. Strategies to Prevent Mycotoxin Contamination of Food and Animal Feed: A Review. Critical Reviews in Food Sci Nut. 2006; 46:593-619.

16. Karimi Ardestani S, Tafvizi F, Tajabadi Ebrahimi M. Molecular detection of heat-killed probiotic bacteria and study of apoptosis induction on colon cancer HT-29 cell line. Iran J Med Microbiol. 2016; 10 (2) :42-52

17. Sarimehmetoglu B, Kuplulu O. Binding Ability of Aflatoxin $M_{1}$ to Yoghurt Bacteria. Ankara Üniversitesi Veteriner Fakültesi Dergisi. 2004; 51:195198.

18. Vinderola G, Itieni A. Role of Probiotics Against Mycotoxins and Their Deleterious Effects. J Food Res. 2015; 4:10-21.

19. Sanders ME. Lactic Acid Bacteria as Promoters of Human Health. In: Goldberg, L. (Ed.), Functional Foods. New York: Chapman and Hall Co; 1997. 294-322.

20. Möller C, De Vrese M. Probiotic Effects of Selected Acid Bacteria. Milchwissenschaft. 2004; 59(11):597-601.

21. Kitazawa H, Harata T, Uemura J, Saito T, Kaneko T, Itoh T. Phosphate Group Requirement for Mitogenic Activation of Lymphocytes by an Extracellular Phosphopolysaccharide From Lactobacillus Delbrueckii ssp. Bulgaricus. Int J Food Microbiology. 1998; 40(1):169-175.

22. Kabak B, Brandon EFA, Var I, Blokland M, Sips, AJAM. Effects of Probiotic Bacteria on Bioaccessibility of Aflatoxin B1 and Ochrtoxin A Using an In Vitro Digestion Model Under Fed Conditions. J Environmental Sci Health. 2009; 44: 472-480.

23. Kahouli I, Malhotra M, Westfall S, Alaoul-Jamall MA, Piakash S. Design and Valldation of an Orally Administrated Active L. Fermentum-L. Acidofillus Probiotic Formulation Using Colorectal Cancer ApcMin/+ Mouse Model. Applied Microbiology Biotech. 2017; 101(1):1999-2019.

24. Kirkpatric W, Lopez-Ribot J, Mcatee R, Patterson T. Growth Competition Between Candida Dublinlensis and Candida Albicans Under Broth and Biofilm Growing Canditions. J Clin Microbiology. 2000; 38(1):902-904. 


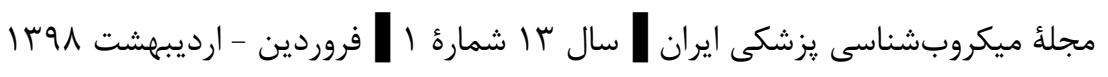

25. Namvar Rad M, Razavilar V, Anvar SAA, AkbariAdergani. Selected Bio-Physical Factors Affecting the Efficiency of Bifidobacterium Animalis Lactis and Lactobacillus Delbrueckii Bulgaricus to Degrade Aflatoxin $\mathrm{M}_{1}$ in Artificially Contaminated Milk. J Food Safety. 2018; 10;1-11.

26. Elsanhoty RM, Salam SA, Ramadan MF, Badr FH. Detoxification of Aflatoxin $\mathrm{M}_{1}$ in Yoghurt Using Probiotics and Lactic Acid Bacteria. Food Control. 2014; 43(1):129-134.

27. Wang JJ, Liu BH, Hsu YT, Yu FY. Sensitive Competitive Direct Enzyme-Linked Immunosorbent Assay and Gold Nanoparticle Immunochromatographic Strip for Detecting Aflatoxin $\mathrm{M}_{1}$ in mMilk. Food Control. 2011; 22(1):964-969.

28. Riazipour M, Tavakkoli HR, Razzaghi AM, Rafati H, Sadr Momtaz, SM. Measuring the Amount of $M_{1}$ Aflatoxin in Pasteurized Milks. Kowsar Medical Journal. 2010; 15(2):89-93.

29. Jawaid S, Talpur, FN, Nizamani SM, Afridi HI. Contamination Profile of Aflatoxin $\mathrm{M}_{1}$ Residues in Milk Supply Chain of Sindh, Pakistan. Toxicology Reports. 2015; 2:1418-1422.

30. Sadat Fakoor Janati S, Beheshti HR, Feizy J, Asadi M. Aflatoxin Determination in Saffron by HighPerformance Liquid Chromatography and Immunoaffinity Column Clean-Up. Saffron Agronomy Tech. 2013; 1(2):102-111.

31. Lopez CE, Ramos LL, Ramadan SS, Bulacio LC. Presence of Aflatoxin $\mathrm{M}_{1}$ in Milk for Human Consumption in Argentina. Food Control. 2003; 14:3134.

32. Bovo F, Corassin CH, Rosim RE, de Oliveira CA. Efficiency of Lactic Acid Bacteria Strains for Decontamination of Aflatoxin $\mathrm{M}_{1}$ in Phosphate Buffer Saline Solution and in Skimmed Milk. Food and Bioprocess Tech. 2013; 6(8):2230-2234.

33. Haskard CA, El-Nezami HS, Kankaanpää PE, Salminen $\mathrm{S}$, Ahokas JT. Surface Binding of Aflatoxin $\mathrm{B}_{1}$ by Lactic
Acid Bacteria. Appl Environ Microbiol. 2001; 67(7):3086-3091.

34. El-Nezami H, Kankaanpaa P, Salminen S, Ahokas J. Ability of Dairy Strains of Lactic Acid Bacteria to Bind a Common Food Carcinogen, Aflatoxin $B_{1}$. Food Chem Toxicol. 1998; 36(4):321-326.

35. Ismail A, Akhtar S, Levin RE Ismail T, Riaz M, Amir M. Aflatoxin $\mathrm{M}_{1}$ : Prevalence and Decontamination Strategies in Milk and Milk Products. Crit Rev Microbiol. 2016; 42(3):418-427.

36. Serrano-Niño JC, Cavazos-Garduño A, HernandezMendoza A, Applegate B, Ferruzzi MG, San MartinGonzález MF, et al. Assessment of Probiotic Strains Ability to Reduce the Bioaccessibility of Aflatoxin $\mathrm{M}_{1}$ in Artificially Contaminated Milk Using an In Vitro Digestive Model. Food Control. 2013; 31(1):202-207.

37. Sarimehmetoğlu B, Küplülü Ö. Binding Ability of Aflatoxin $\mathrm{M}_{1}$ to Yoghurt Bacteria. Ankara Üniv Vet Fak Derg. 2004; 51(1):195-198.

38. Kabak B, Var I. Factors Affecting the Removal of Aflatoxin $\mathrm{M}_{1}$ From Food Model by Lactobacillus and Bifidobacterium Strains. J Environ Sci Health B. 2008; 43(7):617-624.

39. Bueno DJ, Casale CH, Pizzolitto RP, Salvano MA, Oliver G. Physical Adsorption of Aflatoxin $\mathrm{B}_{1}$ by Lactic Acid Bacteria and Saccharomyces Cerevisiae: A Theoretical Model. J Food Prot. 2007; 70(9):2148-2154.

40. Adibpour N, Soleimanian-Zad S, Sarabi-Jamab M, Tajalli F. Effect of Storage Time and Concentration of Aflatoxin $\mathrm{M}_{1}$ on Toxin Binding Capacity of $L$. Acidophilus in Fermented Milk Product. J Agr Sci Tech. 2016; 18(1):1209-1220.

41. Elgerbi AM, Aidoo K, Candlish AAG, Williams AG. Effects of Lactic Acid Bacteria and Bifidobacteria on Levels of Aflatoxin $\mathrm{M}_{1}$ in Milk and Phosphate Buffer. Milchwissenschaft. 2006; 61(2):197-199. 